Experimental study of the material and bond properties of frost-damaged concrete

Kamyab Zandi Hanjari, Peter Utgenannt, Karin Lundgren

Published in Cement and Concrete Research,

http://www.journals.elsevier.com/cement-and-concrete-research/,

full reference:

Zandi Hanjari, K., Utgenannt, P. and Lundgren, K. (2011): Experimental study of the material and bond properties of frost-damaged concrete, Cement and Concrete Research 41 (2011) pp. 244-254, doi:10.1016/j.cemconres.2010.11.007. 


\title{
Experimental study of the material and bond properties of frost-damaged concrete
}

\author{
Kamyab Zandi Hanjari ${ }^{\mathrm{a}, *}$, Peter Utgenannt ${ }^{\mathrm{b}}$, Karin Lundgren ${ }^{\mathrm{a}}$ \\ ${ }^{a}$ Department of Civil and Environmental Engineering, Chalmers University of Technology, \\ 41296 Gothenburg, Sweden \\ ${ }^{b}$ CBI Swedish Cement and Concrete Research Institute, 50115 Borås, Sweden
}

\begin{abstract}
:
In an extensive experimental investigation, several types of tests were conducted on a reference specimen and frost-damaged concrete. Two levels of internal frost damage were quantified by the relative dynamic modulus of elasticity and compressive strength. Test results showed a significant influence of freeze-thaw cycles on the compressive strength and even more influence on the modulus of elasticity and the compressive strain at peak stress. Reduced tensile strength and increased fracture energy were measured. From inverse analysis of wedge splitting test results, a significant effect of frost on the shape of the tensile stresscrack opening relationship was observed: tensile strength was reduced, while the post-peak behaviour was more ductile for the frost-damaged concrete. Pull-out tests showed the influence of freeze-thaw cycles on bond strength and slip. The pull-out test results are compared with similar tests available in the literature and the effect of frost on bond behaviour is discussed.
\end{abstract}

Keywords:

Freezing and Thawing (C); Compressive Strength (C); Tensile Properties (C); Bond Strength (C); Fracture Energy

\section{INTRODUCTION}

One of the severe types of deterioration in concrete structures is associated with the volume expansion of concrete caused by freezing and thawing. When evaluating residual loadcarrying capacity of frost-damaged concrete structures by the finite element method, the effect of internal frost damage can be modelled as a change in material and bond properties [1]. Therefore the effect of frost damage needs to be quantified in terms of material and bond properties.

As the volume expansion of freezing water cannot be accommodated in the pore system of concrete, it is restrained by the surrounding concrete. Thereby, tensile stresses are initiated and micro and macro-cracks are introduced into the concrete body, which leads to a type of damage known as internal frost damage. This mechanism affects the stress-strain relation in compression and tension, as well as compressive and tensile strengths, elastic modulus, fracture energy, and bond strength between the reinforcement and surrounding concrete in damaged regions [2]. Another type of frost damage, known as surface scaling, is caused by mechanisms involving the differing thermal expansion of ice and concrete [3]. This mechanism is involved when a concrete structure is subjected to cold climates in the presence 
of saline water. The present paper deals with the effect of internal frost damage on the material and bond properties of concrete; it does not include the effect of surface scaling.

Several research articles have been primarily concerned with the causes and mechanisms of frost deterioration, see $[4,5,6]$. However, very little attention has been given to the effect of frost damage on the material and bond properties of concrete. Zandi Hanjari [1] showed that the relations between compressive and tensile strength for undamaged concrete cannot be used directly for frost-damaged concrete. A stress-strain model relating to stiffness degradation of concrete subjected to the effect of freezing and thawing cycles has been proposed [7,8]. In their model, a freezing-thawing fracture parameter was introduced, in addition to the fracture parameter for mechanical loading, to express degradation in initial stiffness caused by micro-cracking during freezing and thawing exposure. Shih et al. [9] showed that cyclic temperature changes have a decisive influence on the maximum bond resistance of concrete subjected to monotonic and reversed cyclic loading. Experimental observation proved that the bond stress-slip relation before maximum bond stress is similar for damaged and undamaged concrete [10]. However, the bond capacity and slip at the maximum bond strength change significantly with frost damage [2]. To the authors' knowledge, there have been no tests made to experimentally investigate the stress-strain response of frost-damaged concrete in tension.

The experiments presented here were carried out to investigate the effect of frost damage on the material and bond properties of concrete. Therefore, the level of frost damage was quantified by the relative dynamic modulus of elasticity, calculated from ultrasonic measurements made on all specimens, and by the compressive strength of concrete. The change in microstructure of the concrete was visually observed by microscopic imaging; the distribution of cracks was investigated using image analysis of thin sections. The behaviour of frost-damaged concrete was evaluated in compression, by compression tests and elastic modulus tests, and in tension, by splitting tensile and wedge splitting tests. Crack propagation in wedge splitting tests was monitored by measurements of the strain field using an optical system. The wedge splitting test made it possible to obtain the stress-crack opening, $\sigma-\omega$, and fracture energy of concrete by inverse analysis. Finally, pull-out tests were made to evaluate the effect of frost damage on the bond between the reinforcement and the concrete; the results were also compared with similar tests found in the literature. The outcome of the tests can be used when analyzing frost-damaged concrete structures and to gain a better understanding of the effect of frost damage on properties of concrete.

\section{EXPERIMENTAL PROGRAM}

Several tests were made on a reference specimen and frost-damaged concrete, see Table 1. Since the level of frost damage depends on the shape and size of the specimen, concrete cylinders of $250 \times 100 \mathrm{~mm}$ were cast for all of the tests; these were cut according to Table 1 at the time of testing. Due to limited space in the freezing chamber, the size of the specimens was chosen to be smaller than the standard size, cylinder $300 \times 150 \mathrm{~mm}$. The specimens were exposed to demineralised water to make sure that surface scaling was minimized. Twentyfour hour freeze-thaw cycles at temperatures from $+20{ }^{\circ} \mathrm{C}$ to $-20{ }^{\circ} \mathrm{C}$ were applied. The tests were made on:

a) 28-day cured concrete called reference concrete; 
b) 28-day cured concrete stored in a freezing chamber as long as needed to cause a reduction of $25 \%$ in compressive strength, damage level I; and

c) 28-day cured concrete stored in a freezing chamber as long as needed to cause a reduction of $50 \%$ in compressive strength, damage level II.

Table $1 \quad$ Test program, dimensions in $\mathrm{mm}$.

\begin{tabular}{|c|c|c|}
\hline Frost effect characterization & Test & Specimen dimension \\
\hline \multirow{2}{*}{ Damage quantification } & Ultrasonic transit time & Cylinder $250 \times 100$ \\
\hline & Compression test & Cylinder $200 \times 100$ \\
\hline Microstructure & Thin section analysis & Square $50 \times 80$ \\
\hline \multirow{2}{*}{ Compression behaviour } & Compression test & Cylinder $200 \times 100$ \\
\hline & Elastic modulus test & Cylinder $200 \times 100$ \\
\hline \multirow{3}{*}{ Tensile behaviour } & Splitting tension test & Cylinder $200 \times 100$ \\
\hline & Wedge splitting test & Cylinder $100 \times 100$ \\
\hline & Strain field measurements & Cylinder $100 \times 100$ \\
\hline Bond behaviour & Pull-out test & Cylinder $200 \times 100$ \\
\hline
\end{tabular}

\subsection{Specimens and material}

The concrete was mixed in one batch and moulded into cylinders of $250 \times 100 \mathrm{~mm}$ which were cut to $200 \times 100 \mathrm{~mm}$ specimens $(25 \mathrm{~mm}$ from each side) at the time of testing; more detail is available [11]. The concrete used in this investigation was of grade C35/45, with a water cement ratio of 0.57 ; see Table 2 for mix composition. While casting, concrete was poured into the moulds and compacted in two steps, 20 seconds vibration using a vibrating table for each step. All of the specimens were removed from the moulds after $24 \pm 2$ hours and submerged in tap water at $20 \pm 2{ }^{\circ} \mathrm{C}$ for 7 days. Then they were stored in a climate chamber, with a temperature of $20 \pm 2{ }^{\circ} \mathrm{C}$ and a relative humidity of $65 \pm 5 \%$, for 17 days. The specimens were pre-saturated by storing in tap water at $20 \pm 2{ }^{\circ} \mathrm{C}$ for 3 days. Thereafter, the reference specimens were tested; the others were stored in the freezing chamber to reach the desired levels of frost damage, $25 \%$ and $50 \%$ reduction in compressive strength, for damage levels I and II, respectively. The specimens used for testing at damage levels I and II were also pre-saturated for 3 days prior to testing.

Table $2 \quad$ Concrete mix composition

\begin{tabular}{l|c|c}
\hline \multicolumn{1}{c|}{ Constituents } & $\begin{array}{c}\text { Mix } \\
{\left[\mathrm{kg} / \mathrm{m}^{3}\right]}\end{array}$ & $\begin{array}{c}\text { Density } \\
{\left[\mathrm{kg} / \mathrm{m}^{3}\right]}\end{array}$ \\
\hline Cement (CEM I SR/LA/MH) & 360.0 & 3100 \\
Water & 205.0 & 1000 \\
Aggregate: sand $0-4 \mathrm{~mm}$ & 990.1 & 2530 \\
Aggregate: Gravel $5-10 \mathrm{~mm}$ & 777.9 & 2630 \\
\hline
\end{tabular}

For the pull-out specimens, ribbed hot-rolled bars of the Swedish type K500ST $\varnothing 6 \mathrm{~mm}$ were chosen. The mechanical properties of the reinforcement are given in Table 3; the tensile tests were carried out according to a standard procedure; i.e. SS-EN 10080:2005. 
Table 3 Mechanical properties of the reinforcement

\begin{tabular}{c|c|c|c|c|c}
\hline $\begin{array}{c}A_{s} \\
{\left[\mathrm{~mm}^{2}\right]}\end{array}$ & $\begin{array}{c}f_{s y} \\
{[\mathrm{MPa}]}\end{array}$ & $\begin{array}{c}f_{s u} \\
{[\mathrm{MPa}]}\end{array}$ & $\begin{array}{c}\varepsilon_{s y} \\
{[\%]}\end{array}$ & $\begin{array}{c}\varepsilon_{s 2} \\
{[\%]}\end{array}$ & $\begin{array}{c}\varepsilon_{s u} \\
{[\%]}\end{array}$ \\
\hline 28.2 & 552 & 649 & 3.2 & 24 & 94 \\
\hline
\end{tabular}

\subsection{Freeze-Thaw Exposure}

After 28-day curing, the specimens were placed in a cylindrical water container, $260 \times 110$ $\mathrm{mm}$, and exposed to freeze-thaw cycles in a temperature controlled chamber. This means that the specimens were covered with $5 \mathrm{~mm}$ of demineralized water on all surfaces while they were subjected to repeated freezing and thawing. During the test, the temperature in the freezing chamber for all specimens followed the regime specified in RILEM TC 176-IDC [12]. An example of the actual temperature measured inside a water-container during a few freeze-thaw cycles is shown in Figure 1.

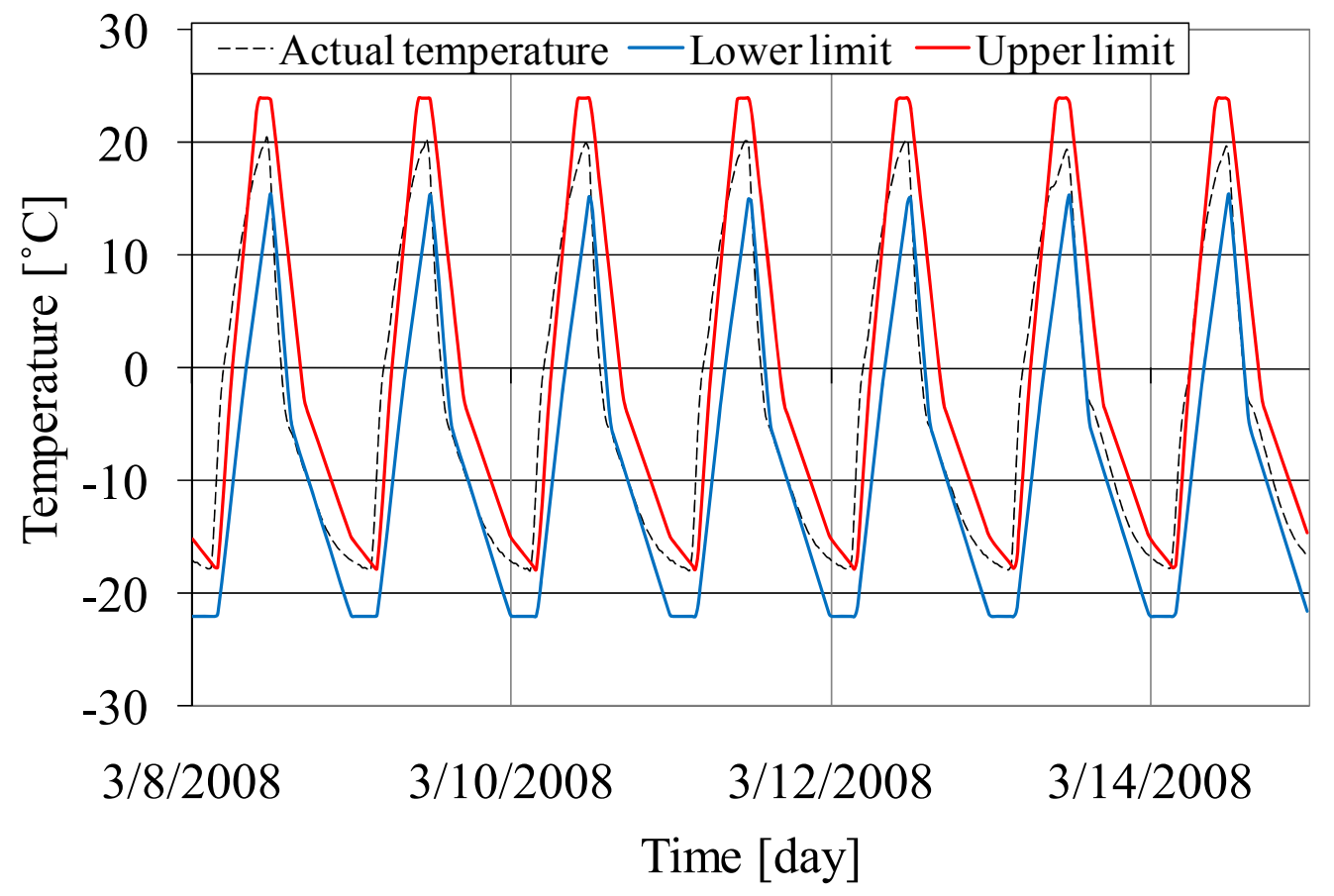

Figure 1 Actual temperature measured inside a water container in the freezing chamber

\section{DAMAGE QUANTIFICATION}

In a pilot study, some tests were conducted on a limited number of concrete cylinders to study how the level of frost damage can be quantified by different methods, as well as how early the frost damage affects concrete compressive strength. The specimens were cast from the same concrete composition as the main study, and they were subjected to freeze-thaw cycles for two weeks. The pilot study included ultrasonic transit time measurements and fundamental transverse frequency tests, carried out every day, as well as compressive tests, made every few days. The results showed that ultrasonic tests were more sensitive to frost damage; the 
measurements were more stable than fundamental transverse frequency tests. Therefore, it was decided to use ultrasonic tests to monitor the level of frost damage in the main study.

In the main study, the level of damage was monitored by ultrasonic measurements of all specimens, after every three freeze-thaw cycles, and by compressive strength tests, when the ultrasonic measurements showed a significant change of transmission time. Once the desired reduction in compressive strength was reached, the specimens were chosen that had approximately the same reduction in the ultrasonic measurements as the one tested in compression. These specimens were removed from the freezing chamber and prepared for testing.

\subsection{Test set-up}

The ultrasonic measurements were based on the RILEM recommendations of the CIF test (capillary suction, internal damage and freeze thaw test) $[13,14]$. During the test, the degree of saturation of a concrete specimen was increased, first by isothermal capillary suction and then by repetition of a well defined freeze-thaw cycle. In addition to ultrasonic transit time, the moisture uptake and surface scaling of the specimens were measured, as a critical parameter, in order to determine the frost resistance; the results of surface scaling are available [11]. Determination of moisture uptake and surface scaling, and the evaluation of the results, were made in accordance with RILEM TC 176-IDC [13,14]. Before capillary suction starts, the specimen length which was to be crossed by the ultrasonic waves was measured to an accuracy of $\pm 0.1 \mu \mathrm{m}$.

The ultrasonic measurements were made for each sample using an AU 2000 Ultrasonic Tester (CEBTP). The wave frequency was $60 \mathrm{kHz}$, the sampling frequency $10 \mathrm{MHz}$ and the time resolution $0.1 \mu \mathrm{s}$. The Ultrasonic Tester was prepared according to the manufacturer's instruction. Sonic conductive grease was applied at the centre of both ends of the specimens. The transducers were positioned on the longitudinal axis of the specimens and pressed against the concrete surface, so that a constant minimum value was reached. Finally, the transmission time to the nearest $0.1 \mu \mathrm{s}$ was read. The ultrasonic transit axis marked on each specimen for the first measurements was used for all subsequent once. For the specimens which were set up for pull-out tests with a rebar in the centre, the transmission times were computed by averaging three ultrasonic measurements, approximately $120^{\circ}$ apart, along the longitudinal axes of the specimens. Measurements were made at the start of the freeze-thaw test (zero freeze-thaw cycles) and after every few cycles. When the first and second levels of frost damage were nearly reached, additional measurements were made after every cycle.

\subsection{Results}

The relative transit time, $\gamma_{\mathrm{n}}$, after $n$ freeze-thaw cycles, was calculated for each specimen:

$$
\gamma_{n}=\frac{t_{n}}{t_{0}}
$$

It is convenient to express internal damage as the relative dynamic modulus of elasticity, $R_{\mathrm{u}, \mathrm{n}}$, from the ultrasonic transit time. Assuming that the ultrasonic transit time is inversely proportional to the fundamental frequency and that the change in the mass of specimens is negligible, the relative dynamic modulus can be calculated: 
$R_{u, n}=\frac{1}{\gamma_{n}{ }^{2}} \times 100[\%]$

where $t_{\mathrm{n}}$ is the transmission time measured after $n$ freeze-thaw cycles, and $t_{0}$ is the initial transmission time before the first freeze-thaw cycle.

The calculated relative dynamic modulus of elasticity versus number of freeze-thaw cycles is shown in Figure 2. It can be seen that for the same number of freeze-thaw cycles, a larger relative dynamic modulus of elasticity was calculated for specimens with rebar. This agrees with the ultrasonic measurements on pull-out tests reported [10]. As explained in Section 3.1, the transmission time of pull-out specimens was measured at three points, equally spaced around the longitudinal axis of the specimens, and the average value was reported. For the other specimens, the transmission time was measured along the longitudinal axis of the specimen. This can be a potential source of error in ultrasonic measurements of pull-out specimens. On the other hand, depending on the type of concrete and rebar, the heat capacity of concrete can be twice as much as the heat capacity of steel rebar. Hence, the pull-out specimens are exposed to different temperature profiles through the surrounding concrete and from the centre of the specimen through steel rebar.

According to RILEM TC 176-IDC [13,14], the concrete is defined as damaged when the relative dynamic modulus of elasticity is less than $80 \%$. It can be seen in Figure 2 that after only 20 freeze-thaw cycles, the relative dynamic modulus of elasticity decreased to $80 \%$. For larger numbers of freeze-thaw cycles, the relative dynamic modulus of elasticity decreased at a lower rate.

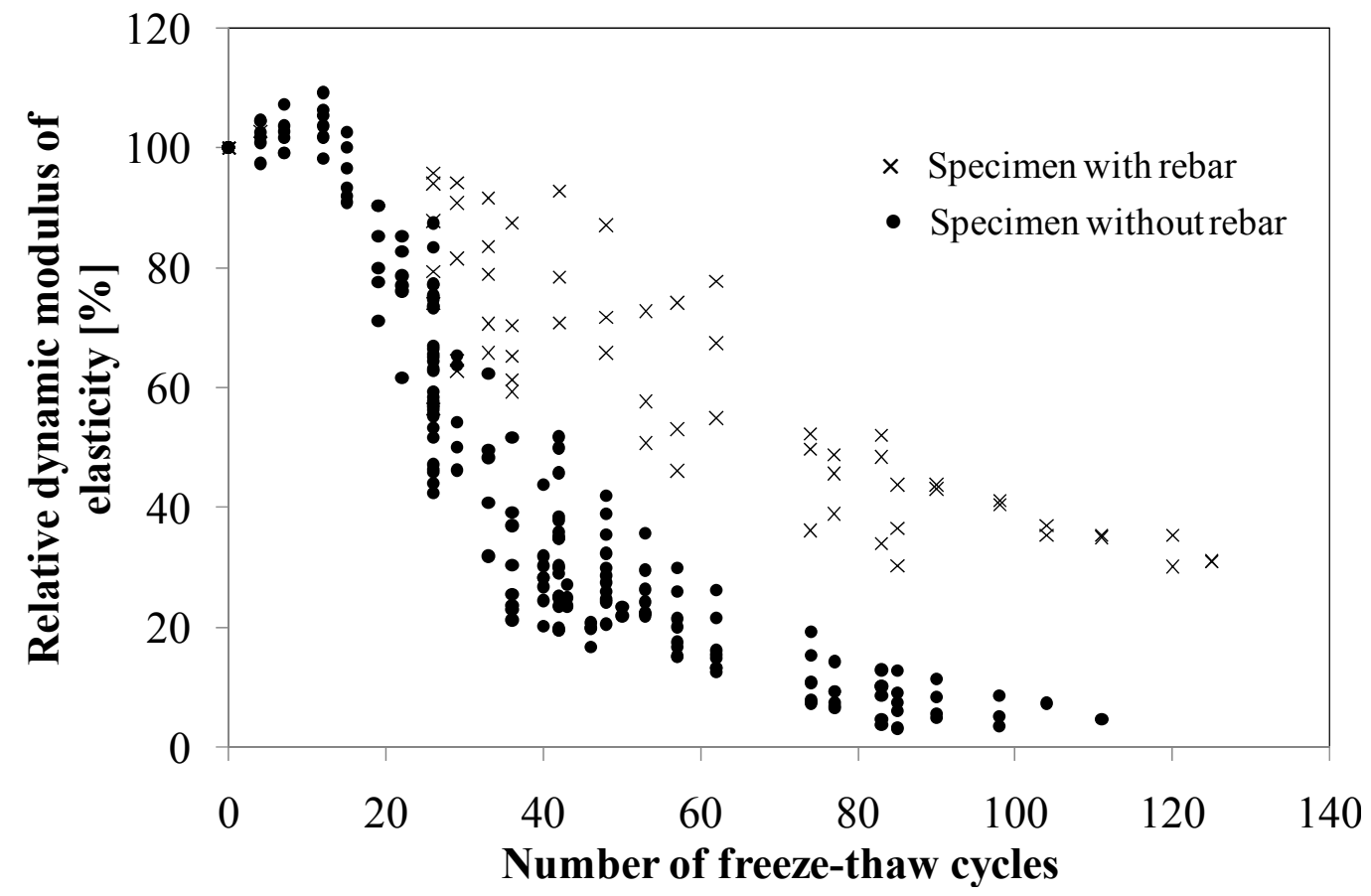

Figure 2 Relative dynamic modulus of elasticity versus number of freeze-thaw cycles 


\section{CHANGE IN MICROSTRUCTURE}

Microscopic technique and analysis of thin sections were used to find evidence of internal frost damage in the microstructure of concrete. Thin sections were cut from the reference concrete and frost-damaged concrete to observe the internal cracking. Figure 3 shows photographs of polished samples impregnated with epoxy resin and fluorescent dye for the reference specimens and frost-damaged concrete. The figure shows internal cracking in frostdamaged concrete, which grows in density with increasing the level of damage.

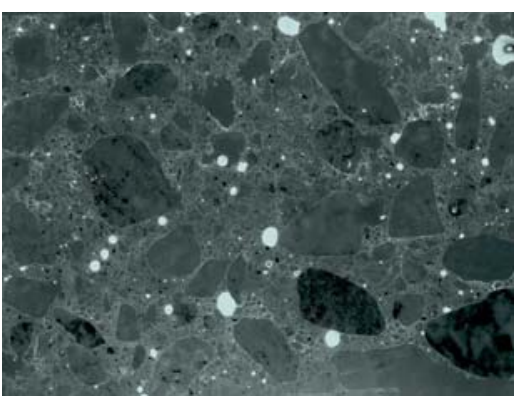

(a)

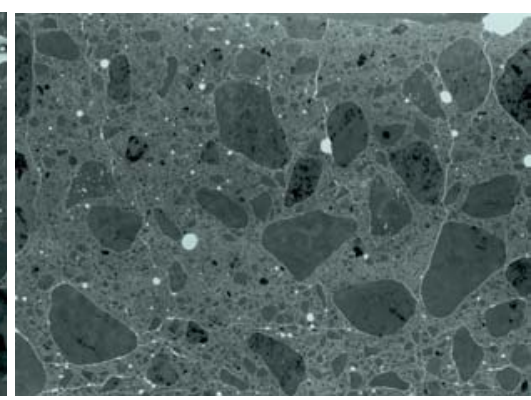

(b)

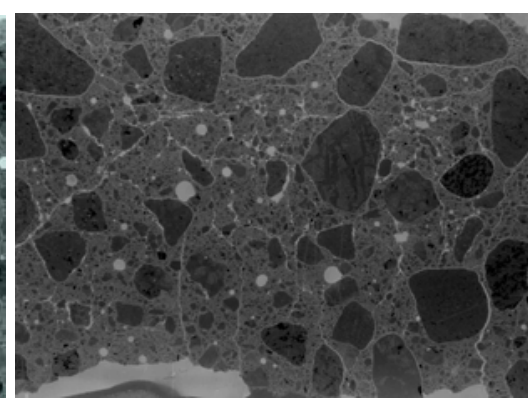

(c)

Figure 3 Distribution of cracks shown in photographs taken by a microscopic imaging system: (a) reference concrete, (b) damage level I, and (c) damage level II.

The crack distribution was determined using image analysis of thin sections. Table 4 presents characteristics of the crack density obtained from microscope observations. A survey of cracks located in the cement paste and at the interfaces between aggregate and cement paste was made. The density of cracks is expressed as number of cracks per unit area. The cracks are differentiated based on crack width; it is clearly seen that the number of cracks is increased with level of frost damage.

Table $4 \quad$ Number of cracks per $m^{2}$ by analysis of thin sections; $w$ is crack width

\begin{tabular}{c|c|c|c|c}
\hline \multirow{2}{*}{ Concrete } & \multicolumn{4}{|c}{ Crack density [n/mm $\left.{ }^{2}\right]$} \\
\cline { 2 - 5 } & $\begin{array}{c}\text { Course crack } \\
0.1<w \\
{[\mathrm{~mm}]}\end{array}$ & $\begin{array}{c}\text { Fine crack } \\
0.01<w<0.1 \\
{[\mathrm{~mm}]}\end{array}$ & $\begin{array}{c}\text { Micro crack } \\
w<0.01 \\
{[\mathrm{~mm}]}\end{array}$ & Adhesion crack \\
& 0.0 & 0.00 & 0.11 & 0.18 \\
\hline Reference & 0.0 & 0.32 & 0.71 & 1.11 \\
Damage level I & 0.00075 & 0.93 & 0.82 & 2.00 \\
\hline
\end{tabular}

\section{COMPRESSION BEHAVIOR}

\subsection{Test set-up}

Compression tests were carried out on cylinders of $200 \times 100 \mathrm{~mm}$ according to the test procedure described in SS-EN 12390-3. The diameter of specimens was determined by averaging three diameter measurements to the nearest $0.25 \mathrm{~mm}$, one at each end of the 
specimen and one at the centre. The specimens were centred in the testing machine and loaded to failure at the rate of 0.2 to $1 \mathrm{MPa} / \mathrm{s}$.

The static modulus of elasticity in compression was determined on $200 \times 100 \mathrm{~mm}$ cylinders according to the test procedure described in SS 1372 32. After the specimens length and diameter were measured as before, they were placed in the compressometer-extensometer, using a nominal $200 \mathrm{~mm}$ gauge length, and carefully seated on the compression machine. In the first loading cycle, the specimen was loaded up to $\sigma_{0}=0.5 \mathrm{MPa}$ and the strain was $\varepsilon_{0}$. The loading was continued at the specified rate of $0.8 \pm 0.2 \mathrm{MPa} / \mathrm{s}$ until a stress level equal to $\sigma_{1}=$ $0.45 f_{\mathrm{cm}}$ was reached. The load was kept at this level for 60 seconds and the strain, $\varepsilon_{1}$, was read. If the differences between each strain, $\varepsilon_{0}$ and $\varepsilon_{1}$, and the mean value were larger than $20 \%$, the same procedure was repeated. When the differences between each strain and the mean value were smaller than $20 \%$, the load was lowered until the initial stress level of $\sigma_{0}$ was reached and kept for 60 seconds. Then, loading was continued at the same rate until a stress level of $\sigma_{2}=0.30 f_{\mathrm{cm}}$ was reached, and followed by unloading to a stress level of $\sigma_{0}$. The load was kept constant for 60 seconds at both stress levels of $\sigma_{2}$ and $\sigma_{0}$. This loading cycle was repeated once again. If the differences between $\varepsilon_{0}$ and $\varepsilon_{2}$, corresponding to $\sigma_{2}$, and the mean value were smaller than $20 \%$, the specimen was loaded to failure and the static modulus of elasticity was calculated accordingly.

\subsection{Results and discussion}

The results from compression and elastic modulus tests are given in Table 5. For damage level II, the compressive strength was too low, $20.4 \mathrm{MPa}$, which made it impossible to conduct the elastic modulus test. The reason was that the loading machine was incapable of functioning at such a low load as the second loading cycle, $0.30 f_{\mathrm{cm}}=6.12 \mathrm{MPa}$. The compressive stress versus compressive strain of $200 \times 100 \mathrm{~mm}$ cylinder specimens is shown in Figure 4. The scatter of the results is higher for frost-damaged concrete than for the undamaged concrete. This can also be noted from the coefficient of variation (Cov) in Table 5. A reduction in compressive strength of concrete by $27 \%$ and $50 \%$ for damage levels I and II, respectively, corresponds to a reduction in elastic modulus by 43 and $84 \%$. The frostdamaged concrete exhibits a larger strain at the peak stress and a more ductile behaviour in the descending branch compare to undamaged concrete.

Table $5 \quad$ Compression and elastic modulus tests results

\begin{tabular}{c|c|c|c|c}
\hline \multirow{2}{*}{ Concrete } & \multicolumn{2}{|c|}{ Compression test } & \multicolumn{2}{c}{ Elastic modulus test } \\
\cline { 2 - 5 } & $\begin{array}{c}f_{\mathrm{cm}} \\
{[\mathrm{MPa}]}\end{array}$ & $\begin{array}{c}\text { Cov } \\
{[\%]}\end{array}$ & $\begin{array}{c}E_{\mathrm{c}} \\
{[\mathrm{GPa}]}\end{array}$ & $\begin{array}{c}\text { Cov } \\
{[\%]}\end{array}$ \\
\hline Reference & 40.6 & 0.94 & 26.6 & 4.13 \\
Damage level I & 29.7 & 10.02 & $15.2^{*}$ & 7.57 \\
Damage level II & 20.4 & 5.31 & $4.2^{* *}$ & 4.58 \\
\hline
\end{tabular}

*This is the average of two specimens

** It was not possible to make the elastic modulus test due to very low compressive strength; instead the elastic modulus is calculated from compressive stress-strain curves.

The ascending branch of the stress-strain curve of the frost-damage concrete is subjected to a sudden change of the stiffness. A possible physical explanation is that freeze-thaw cycles have already introduced many randomly oriented cracks into the concrete before the specimen was subjected to loading; see Figure 3. Consequently, loading starts on a concrete specimen 
of low stiffness before the cracks perpendicular to the stress direction are closed, and then the loading continues with a stiffer concrete. However, the stiffness never fully recovers and a permanent stiffness loss is observed. This agrees with the observation of Shang and Song [15], who investigated the stress-strain curve for plain concrete under biaxial compression, subjected to cycles of freezing and thawing. They observed a different shape of the stressstrain curve for frost-damaged concrete, i.e. the biaxial compressive strain at the peak stress rises with increased level of frost damage. Similar behaviour has been seen in four-point bending tests made on frost-damage beams by Hassanzadeh and Fagerlund [16].

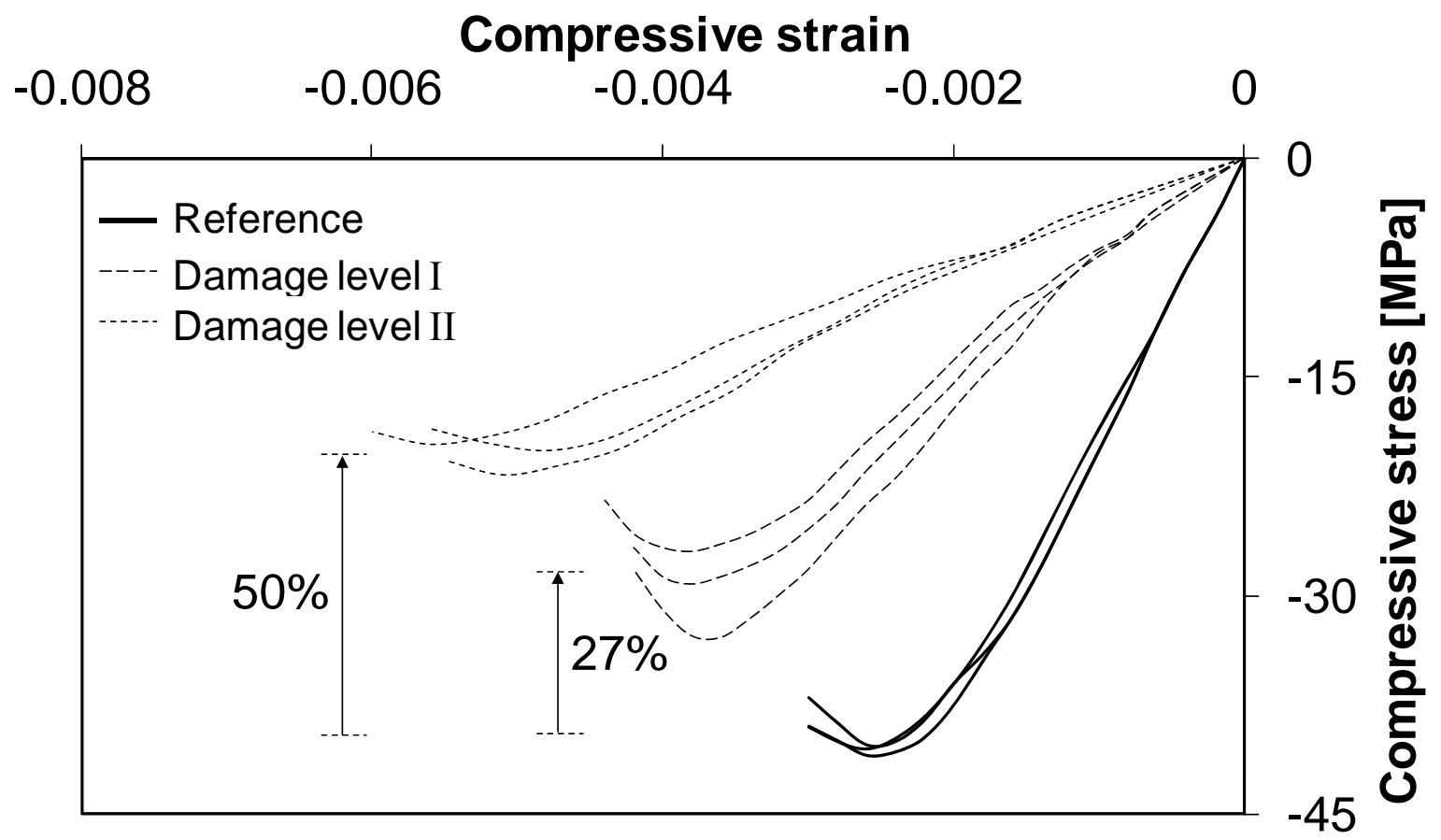

Figure 4 Compressive stress versus strain of $200 \times 100 \mathrm{~mm}$ cylinder specimens.

A comparison of the experimentally observed stress-stain relation versus an analytical model proposed in Ueda [17] is shown in Figure 5. In the model, an elastic bilinear stress-strain relationship is counted for concrete in compression in which an initial stiffness, $k_{1}$, is adopted until reaching a total strain of $\left(\varepsilon_{\mathrm{pa}}+\varepsilon_{\mathrm{pf}}\right)$. For any larger strain a fully recovered stiffness, $\mathrm{k}_{\mathrm{n}}$, is assumed meaning that the envelope of the stress-strain relation for undamaged concrete is considered. Mesoscale plastic tensile strain, $\varepsilon_{\mathrm{pf}}$, depends on the degree of frost damage and $\varepsilon_{\mathrm{fa}}$ is a material constant with a value of 0.0004 as suggested in [17]. The model provides a good estimation of the initial stiffness and the strain at which the stiffness changes. However, the assumption of fully recovered stiffness seems to be an overestimation of the actual stiffness. 


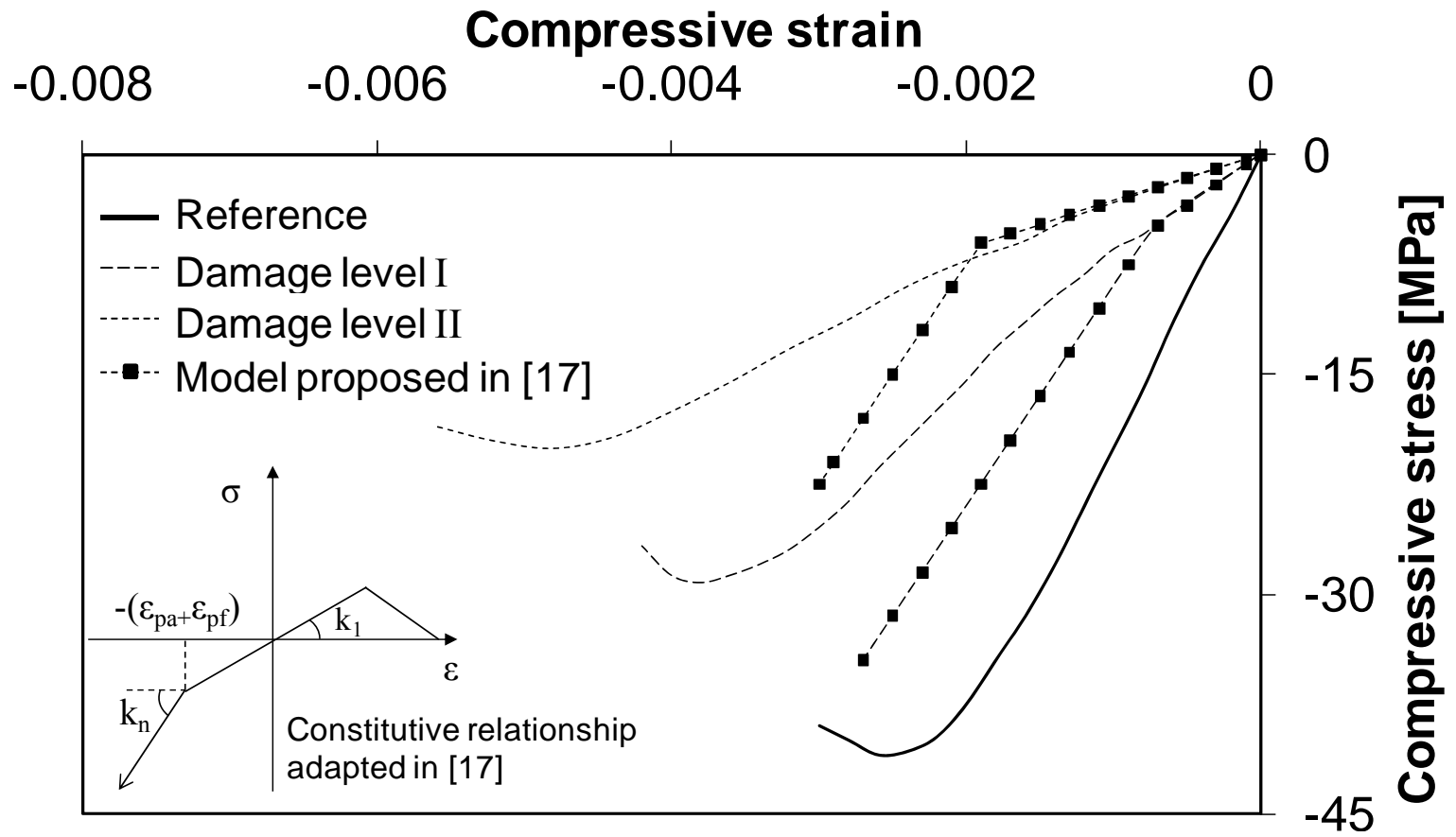

Figure 5 Average compressive stress versus strain of $200 \times 100 \mathrm{~mm}$ cylinder specimens and the model proposed in [17].

\section{TENSILE BEHAVIOUR}

\subsection{Test set-up}

Splitting tensile tests were made on cylinders of $200 \times 100 \mathrm{~mm}$ according to the test procedure described in EN 12390-6:2000. The height of the concrete specimens was computed by averaging two length measurements, approximately $180^{\circ}$ apart, to the nearest $0.25 \mathrm{~mm}$. The diameter of specimens was determined as before, Section 5.1. Two diametric lines opposite each other on the curved surface, $180^{\circ}$ apart, were drawn on the concrete specimens. A plywood strip was glued along each of these diametric lines before the specimen was centred in the compression machine. The pressure head of the compression machine was slowly lowered to the top of the plywood strip until there was just enough pressure for the specimen to be held in place. A steady load at an approximate rate of 0.04 to $0.06 \mathrm{MPa} / \mathrm{s}$ was applied, and the load at failure was recorded. Finally, the splitting tensile strength of the concrete cylinders was calculated accordingly.

In Figure 6, the test set-up, loading procedure and specimen geometry of the wedge splitting test are illustrated. Two steel plates were glued to the specimen (to facilitate applying the splitting load), and a starter notch was cut (to ensure the crack propagation). Slip between the glued steel plates and the specimen was monitored using four linear variable displacement transducers (LVDT). Two steel loading devices with roller bearings were placed on either side of the groove at the top of the specimen. The splitting force, $F_{\mathrm{sp}}$, was applied through a wedging device. During the test, the vertical load, $F_{\mathrm{v}}$, and the crack mouth opening displacement (CMOD), at the same level as the splitting load, were monitored. 
The wedge splitting tests were conducted in a deformation controlled testing machine (screw driven). The initial rate of the vertical displacement was approximately $0.25 \mathrm{~mm} / \mathrm{min}$, which resulted in a CMOD rate of 25 to $50 \mu \mathrm{m} / \mathrm{min}$ before cracking was initiated. As the crack was propagating, the CMOD rate increased until it stabilized at a constant rate of $0.2 \mathrm{~mm} / \mathrm{min}$. The CMOD was measured with an MTS clip gauge (gauge length of $10 \mathrm{~mm}$ and maximum travel of $5 \mathrm{~mm}$ ), placed in the groove. In addition, the horizontal deformation at the centre of the roller bearings was measured with two LVDT gauges (type D2/200A/256 from RDP Group UK) with a stroke of $\pm 5 \mathrm{~mm}$ and an accuracy better than $\pm 0.1 \%$. The slip of the steel plates relative to the concrete specimen was measured for both sides with two LVDT gauges of the same type. The vertical deformation was measured with another LVDT gauge. In the tests, a wedge angle of $15^{\circ}$ was used; the roller bearings were of the double row, deep groove type from SKF (designation 4205 ATN9).

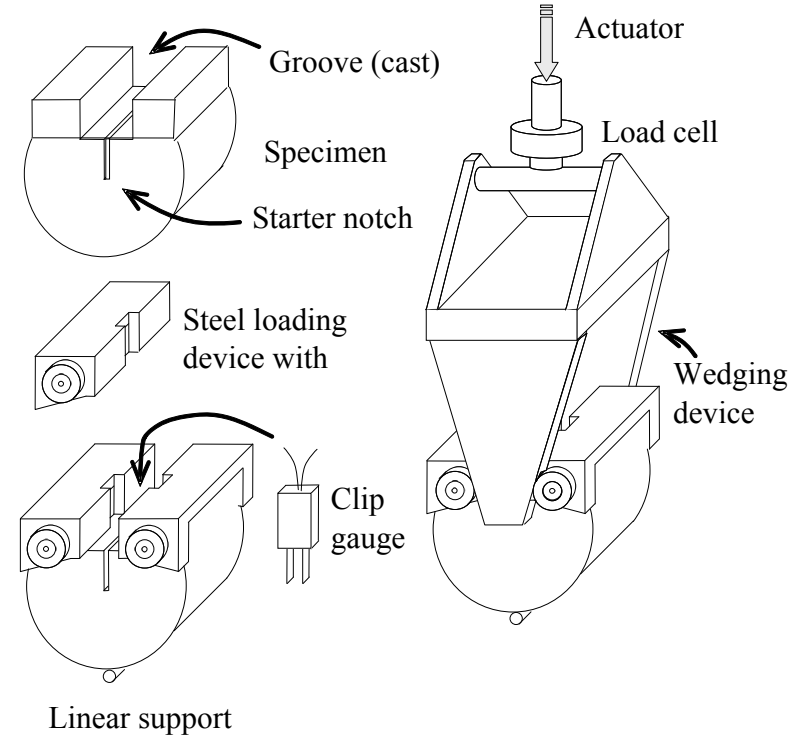

(a)

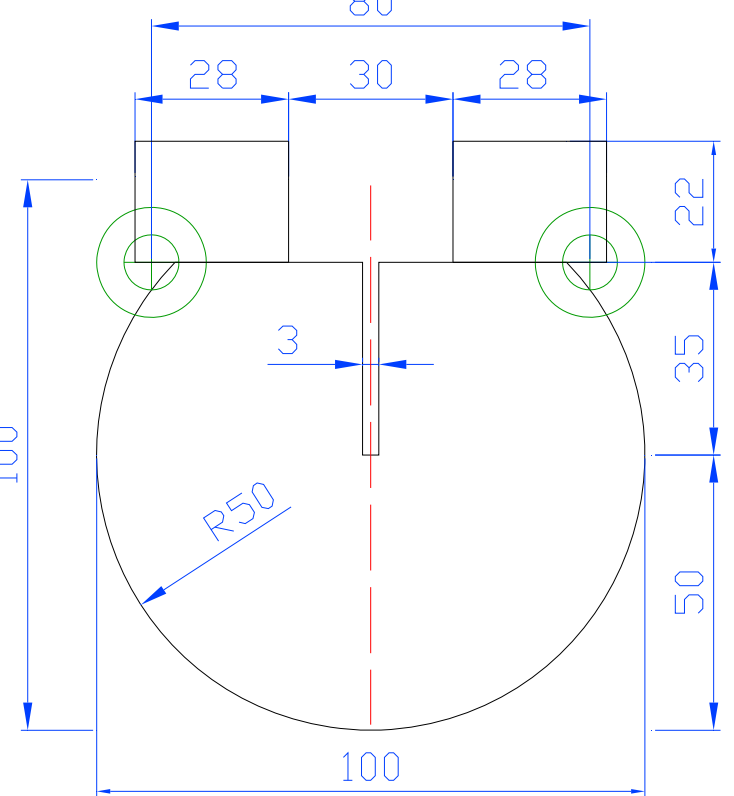

(b)

Figure 6 (a) Schematic view of the wedge splitting test set-up, modified from [19], and (b) Dimensions of the wedge splitting test specimens

Traditionally, the measurement on a wedge splitting test is done by using clip gauge and LVDTs. By this method, although the CMOD is measured for the crack initiated from the tip of the notch and propagating down to the support, the strain in the entire crack pattern is not measured. This method of measurement is accurate enough for plain concrete, in which the brittle tensile behaviour causes a single dominant crack following the notch.

Extensive cracks introduced to the concrete due to frost effect prior to mechanical loading, see Figure 3, caused a network of fine cracks with several dominant cracks, while the wedge splitting test was in progress. However, the crack pattern could not be observed by naked eye. Optical measurement techniques, as a method for high precision measurements of strain and displacement in engineering applications, were used to observe the entire strain field of one wedge splitting specimen. 
The results from compression and splitting tensile tests together with the tensile strength estimated by inverse analysis of wedge splitting test results, see Section 6.3, are presented in Table 6 . From the results it appears that $25 \%$ and $50 \%$ reductions in compressive strength due to frost damage led to approximately $29 \%$ and $63 \%$ reductions, respectively, in splitting tensile strength. A slightly larger reduction in tensile strength than in compressive strength agrees well with what has been observed by other researchers $[16,18]$. Authors of the current articles believe that this is due to extensive cracking formed as a result of freeze-thaw cycles. Cracks perpendicular to the direction of testing cause reduction in tensile strength; in compressive strength these cracks are forced to close again. The differences between the tensile strength as estimated by the splitting tensile test and the wedge splitting test are around $10 \%$.

Table $6 \quad$ Compression and tensile test results

\begin{tabular}{c|c|c|c|c|c}
\hline \multirow{2}{*}{ Concrete } & \multicolumn{2}{|c|}{ Compression test } & \multicolumn{2}{c|}{ Splitting tensile test } & Wedge splitting test \\
\cline { 2 - 6 } & $\begin{array}{c}f_{\mathrm{cm}} \\
{[\mathrm{MPa}]}\end{array}$ & $\begin{array}{c}\text { Cov } \\
{[\%]}\end{array}$ & $\begin{array}{c}f_{\mathrm{t}} \\
{[\mathrm{Mpa}]}\end{array}$ & $\begin{array}{c}\text { Cov } \\
{[\%]}\end{array}$ & $\begin{array}{c}f_{\mathrm{t}} \\
{[\mathrm{Mpa}]}\end{array}$ \\
\hline Reference & 40.6 & 0.94 & 3.8 & 10.1 & 3.4 \\
Damage level I & 29.7 & 10.02 & 2.7 & 5.7 & 2.4 \\
Damage level II & 20.4 & 5.31 & 1.4 & 8.3 & 1.3 \\
\hline
\end{tabular}

In the wedge splitting tests, the applied horizontal splitting force, $F_{\mathrm{sp}}$, is related to the vertical compressive load, $F_{\mathrm{v}}$ :

$$
F_{s p}=\frac{F_{v}}{2 \cdot \tan (\alpha)} \cdot \frac{1-\mu \cdot \tan (\alpha)}{1+\mu \cdot \cot (\alpha)} \approx 1.866 \cdot F_{v}
$$

where $\alpha$ is the wedge angle (here $\alpha=15$ degrees), and $\mu$ is the coefficient of friction for the roller bearing. The coefficient of friction normally varies between $0.1 \%$ and $0.5 \%$. If the friction is disregarded in Eq. (3) (as in this study), the resulting effect on the splitting force, $F_{\text {sp }}$, is about $0.4 \%$ to $1.9 \%$.

The splitting force plotted versus CMOD measured in the experiments for the reference specimens and damage levels I and II is shown in Figure 7. Each curve represents the average value of three tests, except for damage level II which represents the average values of two tests. As can be seen, frost damage not only caused a significant reduction in the maximum splitting load (20\% and $66 \%$ reduction for damage levels I and II, respectively), but it also increased the CMOD value measured at the maximum load. The test of the reference and damage level I specimens could be continued until the splitting force decreased to zero. For damage level II, since the frost damage caused a much softer behaviour of the concrete, measurements of the CMOD could not be made until the splitting load dropped to zero. 


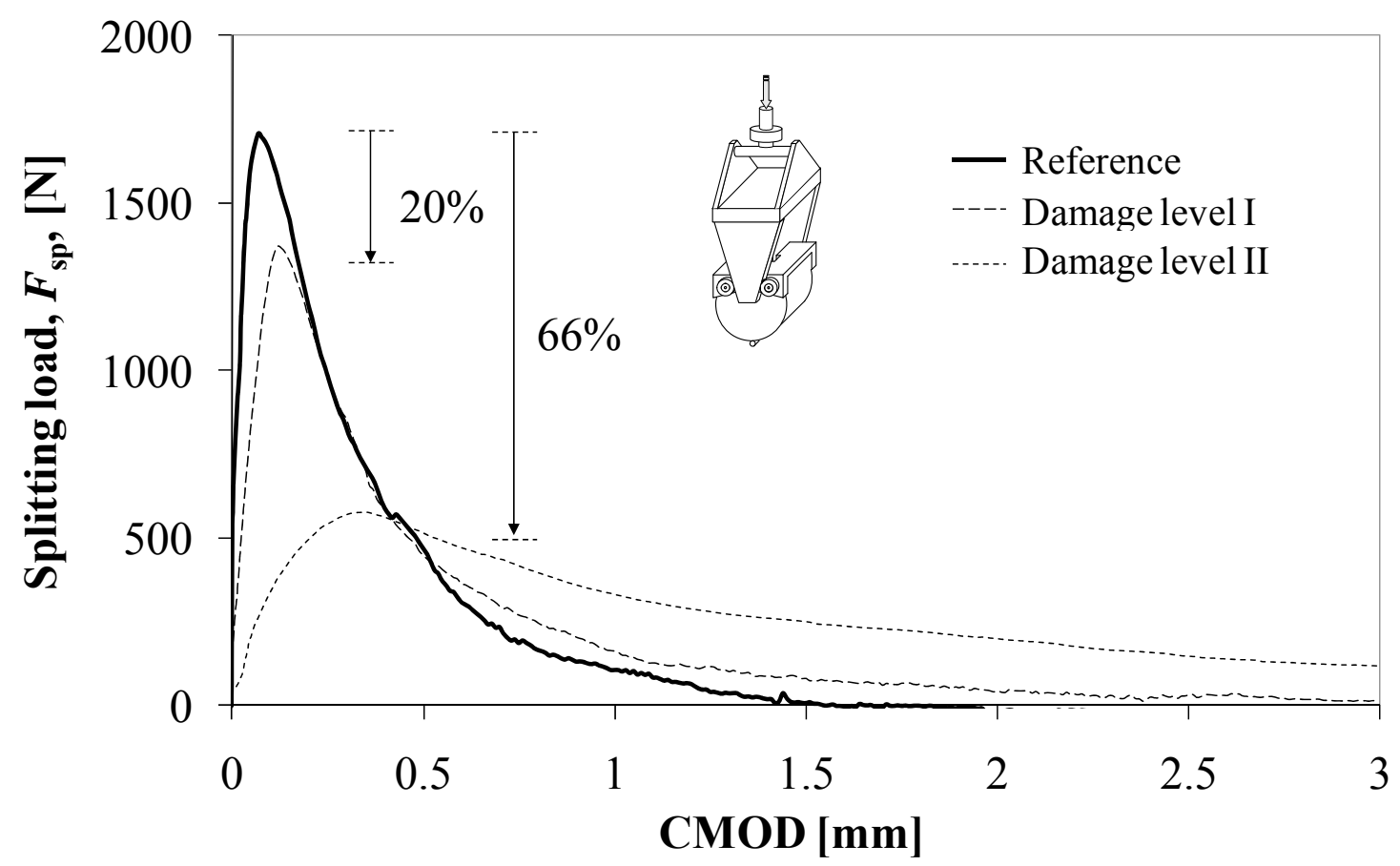

Figure $7 \quad$ Splitting load versus CMOD from wedge splitting tests

At a CMOD equal to $3 \mathrm{~mm}$, the energy dissipated during fracture, $W_{\mathrm{fCMOD}}$, was normalized with respect to the total ligament area, $A_{\text {lig, }}$ at complete fracture. This specific fracture energy is denoted $G_{\mathrm{fCMOD}}\left[\mathrm{Nm} / \mathrm{m}^{2}\right]$, and can be determined directly from the test results:

$G_{f C M O D}=\frac{W_{f C M O D}}{A_{\text {lig }}}$

where $W_{\mathrm{fCMOD}}$ is the area under the splitting load versus CMOD curve and $A_{\text {lig }}$ is the area of the ligament (all of the expected total cracked area). The calculated dissipated energy versus CMOD for the reference specimens and damage levels I and II concrete is shown in Figure 8. The total energy dissipated to fracture a wedge splitting specimen to a CMOD of $3 \mathrm{~mm}$ increased for the higher level of frost damage. This can be explained by the observations with the optical measurement system, Figure 9, which show that more than one dominant crack and several finer cracks were initiated and propagated for frost-damaged concrete. Therefore, higher energy needed to be dissipated to fully fracture a wedge splitting specimen. The photographs taken with the optical measurement system showed that the first cracks started from the tip of the notch and propagated down to the support. After the peak load, other cracks, oriented in different directions, formed. At the end of the test, a network of the fine cracks together with several dominant cracks oriented vertically and horizontally could be observed. 


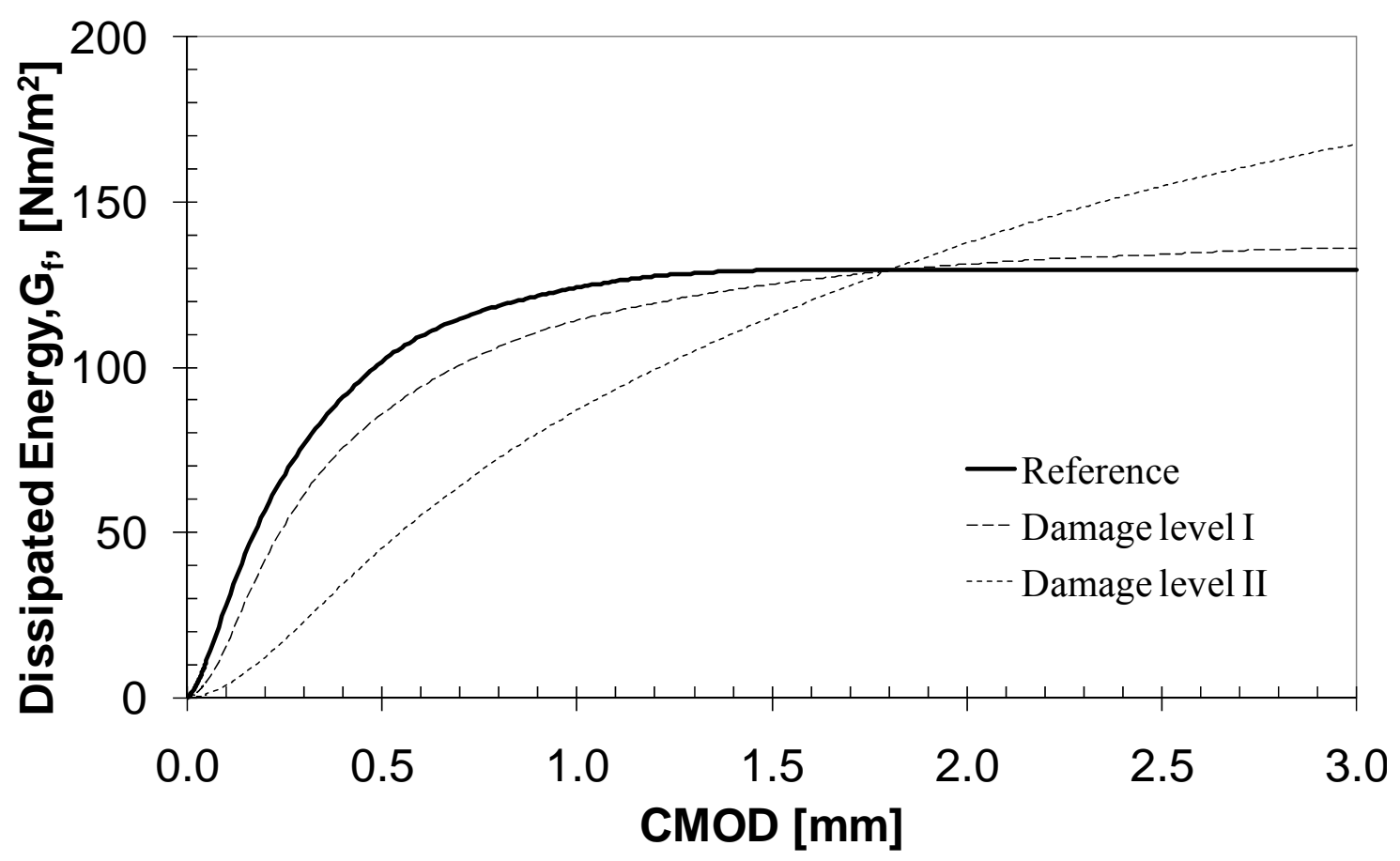

Figure 8 Dissipated energy versus CMOD calculated from wedge splitting test results

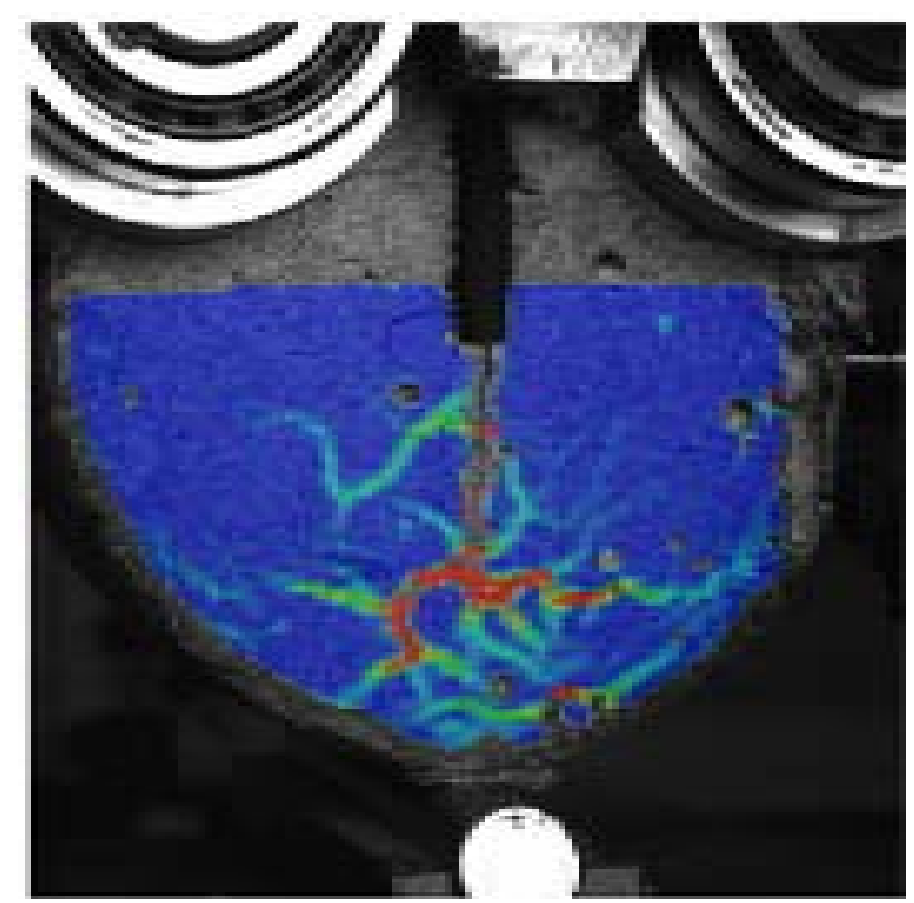

Figure $9 \quad$ Photograph taken by the optical measurement system from wedge splitting specimen of the series "damage level II"

\subsection{Inverse analysis}

The results from the wedge splitting tests can be treated by inverse analysis in order to estimate the relation between tensile stress, $\sigma$, and crack opening, $w$. The $\sigma-w$ relationship can be determined by bi-linear, exponential or poly-linear (multi-linear) approximations. The 
approximation is achieved by minimizing the difference between calculated displacement and target displacement, e.g. CMOD, obtained from the wedge splitting test results; see Figure 10. For a more comprehensive review of inverse analysis, see $[19,20]$.

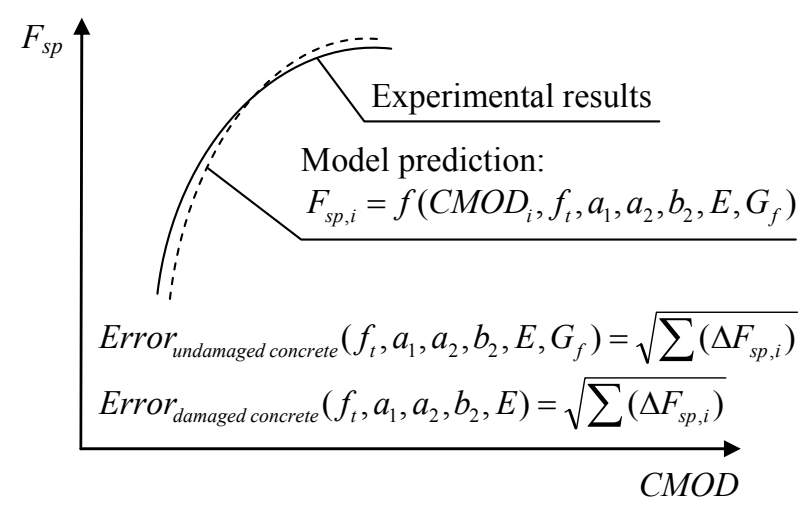

(a)

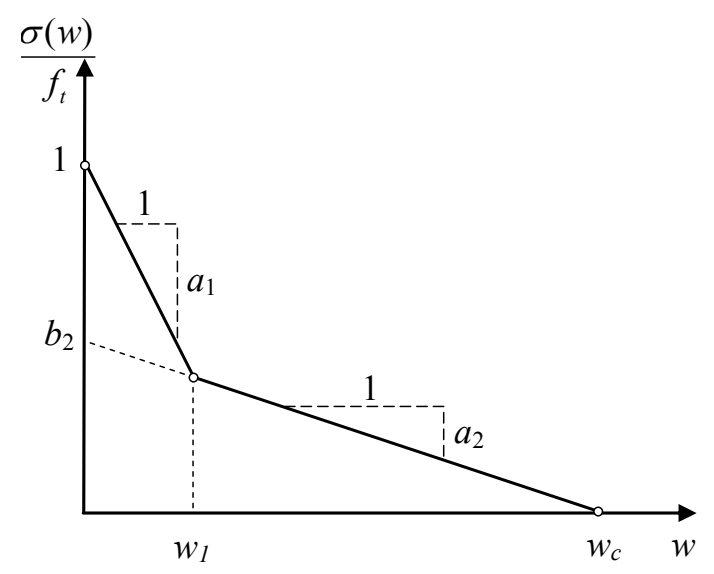

(b)

Figure 10 Principle of inverse analysis: (a) modified optimizing algorithm for frostdamaged concrete, and (b) bi-linear $\sigma$-w relationship.

The inverse analysis in this study was conducted by using a Matlab ${ }^{\circledR}$ program developed at the Technical University of Denmark by Østergaard [21]. The program determines a bi-linear relationship based on the crack hinged model. The response was determined until a CMOD for which the experimental data was available. The estimated constitutive parameters were tensile strength, $f_{\mathrm{t}}$, factors $a_{1}, a_{2}$ and $b_{2}$ defined in Figure 10 (b), elastic modulus, $E$, and fracture energy, $G_{\mathrm{f}}$. The program was modified with respect to the geometry of the concrete specimens and the depth of the starter notch to calculate the total ligament area, $A_{\text {lig, at }}$ complete fracture. For frost-damaged concrete, the optimizing algorithm was also modified so that the fracture energy was not an estimated constitutive parameter but an input to the optimizing algorithm. This modification was necessary since no solution was found for the optimizing problem due to the large fracture energy of frost-damage concrete in comparison with undamaged concrete.

The reliability of the estimated $\sigma$ - $w$ relationship depends on the minimized error between calculated CMOD in inverse analysis and target CMOD in the experiment. This is presented in Figure 11 (a, c and e) in terms of splitting force versus CMOD from experiments and inverse analysis; good agreement is seen in all three cases.

The bi-linear $\sigma-w$ relation from inverse analysis and exponential $\sigma$-w relation from Hordijk et al. [22] are compared in Figure $11(\mathrm{~b}, \mathrm{~d}$ and $\mathrm{f})$. The $\sigma-w$ relation estimated by Hordijk et al. has been calibrated for undamaged concrete; therefore, as expected the agreement is good for reference concrete and less good for frost-damaged concrete. The bi-linear $\sigma$-w relation from inverse analysis of the wedge splitting test of frost-damaged concrete can be used as input data in finite element analysis of concrete structures. 


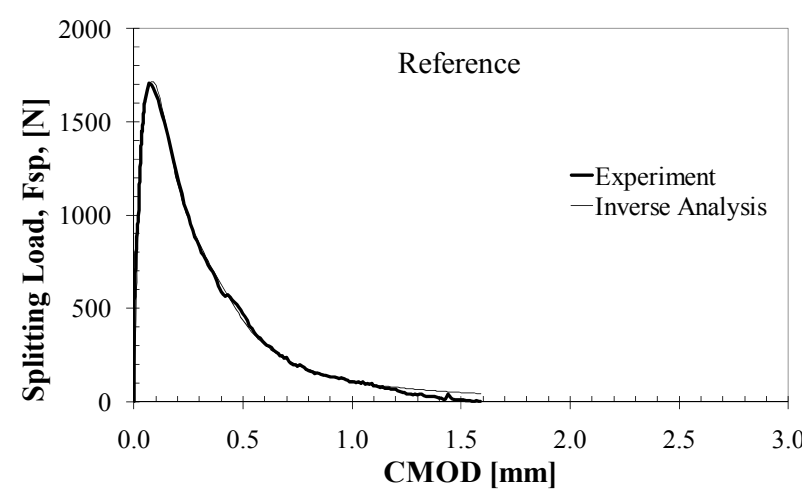

(a)

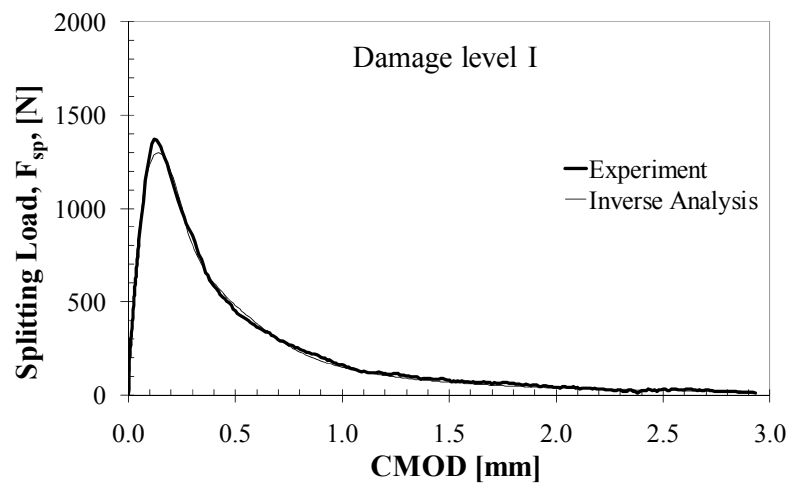

(c)

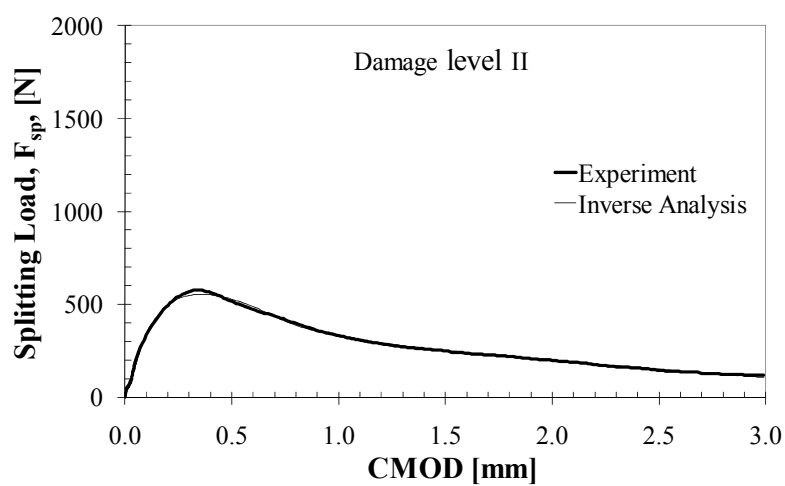

(e)

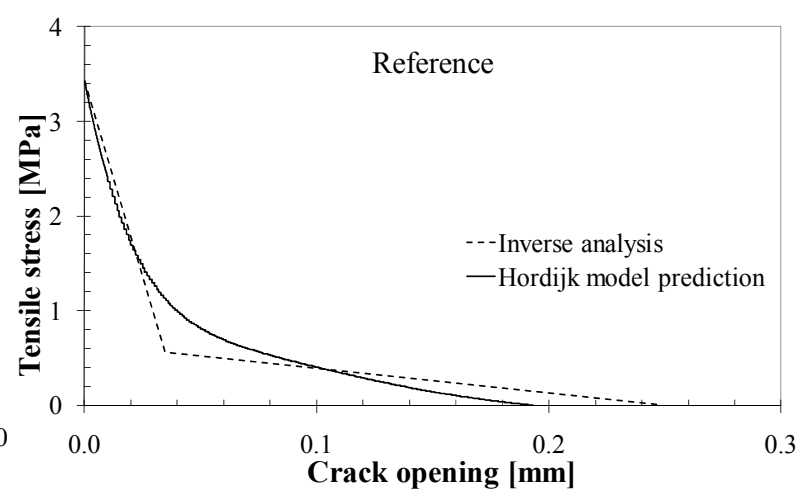

(b)

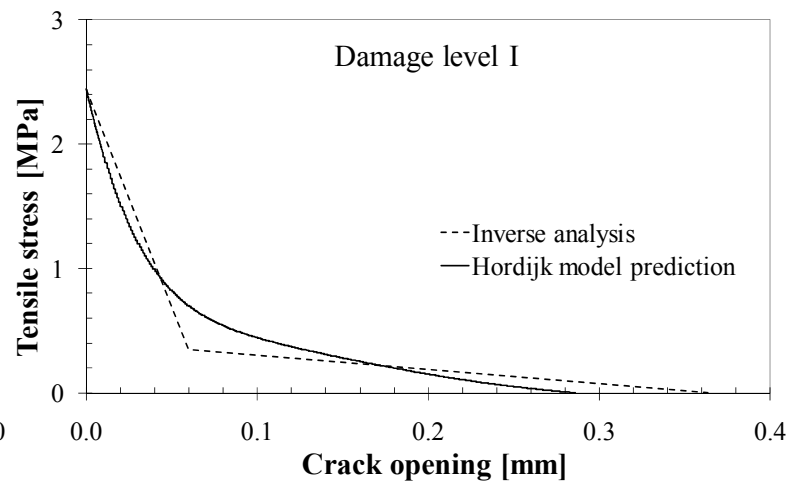

(d)

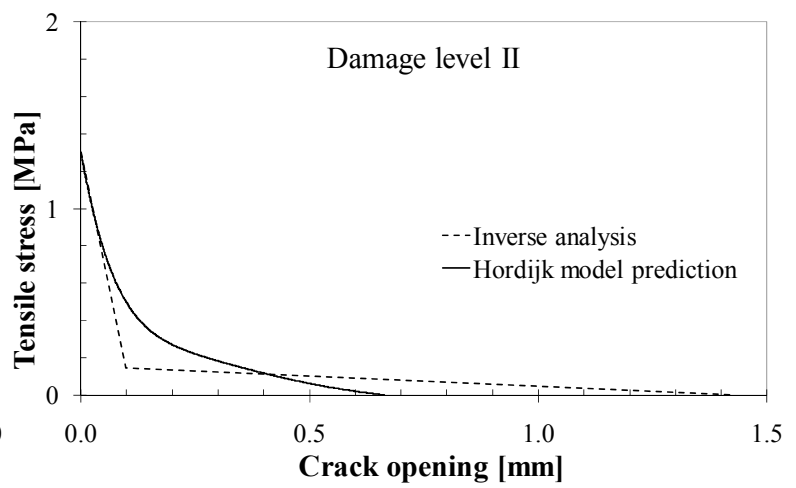

(f)

Figure 11 (a), (c) and (e) Minimized error between calculated CMOD in inverse analysis and target CMOD in the experiment in terms of splitting force versus CMOD, (b), (d) and (f) estimated $\sigma$-w relationship for reference concrete and damage levels I and II. 


\section{BOND BEHAVIOUR}

\subsection{Test set-up}

The pull-out tests were designed to investigate the effect of frost on the local bond-slip relationship under well confined conditions. Therefore, the specimens should have been large enough not only to prevent splitting cracks but also to provide sufficient confinement to get pull-out failure. Since the pull-out specimens were $200 \times 100 \mathrm{~mm}$, the rebar diameter was chosen so that pull-out failure would take place. Nine moulds were arranged for pull-out tests by placing a rebar of $\varnothing 6 \mathrm{~mm}$ on the axis through the centre of the cylinder. The geometry of the specimens is given in Figure 12 (a). The rebar was fixed by a plastic cone on the bottom plate and a wooden cross on the top of the mould. The embedment length was three times the bar diameter, i.e. $18 \mathrm{~mm}$, which included 4 ribs; see Figure 12 (b). The number of ribs and their location along the embedment length were kept constant in all specimens. The bars were debonded outside the embedment length by a plastic tube and the transition between the naked bar and the plastic tube was plunged with wax. This ensures a well-defined embedment length. The bar, plastic tube and plastic cone for fixing the rebar in the moulds were assembled as shown in Figure 12 (a).

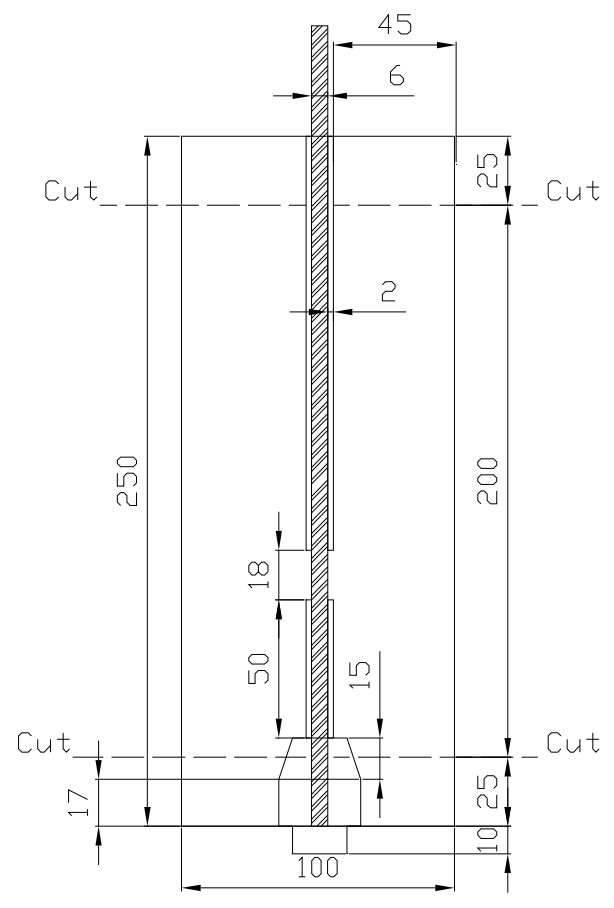

(a)

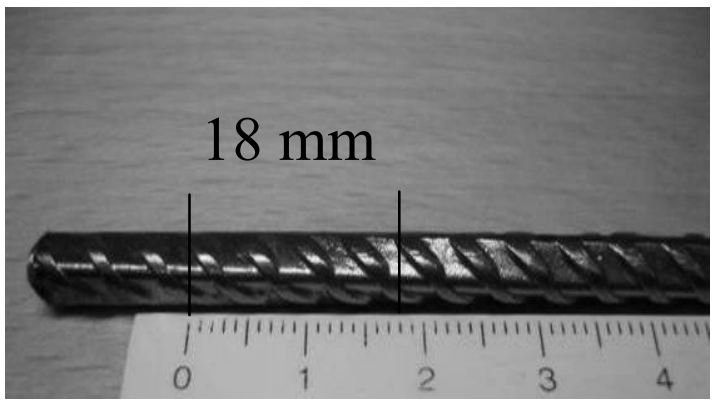

(b)

Figure 12 (a) Geometry of the pull-out specimen and (b) rebar

The tests were conducted in a displacement controlled regime, which means that the active end-slip increased at a constant rate. The displacement rate was increased in steps when the slip reached selected values according to Table 7 . The prescribed displacement was applied in the direction opposite to that of the casting. 
Table $7 \quad$ Displacement controlled loading in pull-out tests.

\begin{tabular}{c|c|c}
\hline $\begin{array}{c}\text { Active end-slip } \\
{[\mathrm{mm}]}\end{array}$ & $\begin{array}{c}\text { Displacement rate } \\
{[\mathrm{mm} / \mathrm{min}]}\end{array}$ & $\begin{array}{c}\text { Test duration } \\
{[\mathrm{min}]}\end{array}$ \\
\hline $0-2.5$ & 0.1 & 25 \\
$2.5-5$ & 0.25 & 10 \\
$5-10$ & 0.5 & 10 \\
$10-25$ & 1.5 & 10 \\
\hline
\end{tabular}

The active and passive end-slips of the reinforcement bar were measured by five linear LVDTs. Four LVDTs were positioned at the passive end-slip, and one at the active end-slip. All data were stored in a personal computer and the active end-slip was plotted continuously versus the load by a xy-plotter.

\subsection{Results}

The bond stress-slip response was deduced by converting the measured forces from the pullout tests into bond stresses:

$$
\tau_{b}=\frac{F}{\pi \cdot \phi \cdot l_{e}}
$$

where $F$ is the force, measured in the pull-out test, $\varnothing$ is the nominal bar diameter, and $l_{\mathrm{e}}$ is the embedment length. More details of measurements, such as the actual embedment length and the maximum measured tensile force for each of the pull-out specimens have been reported [11]. The bond-slip response for different levels of frost damage characterized by the relative dynamic modulus of elasticity is shown in Figure 13.

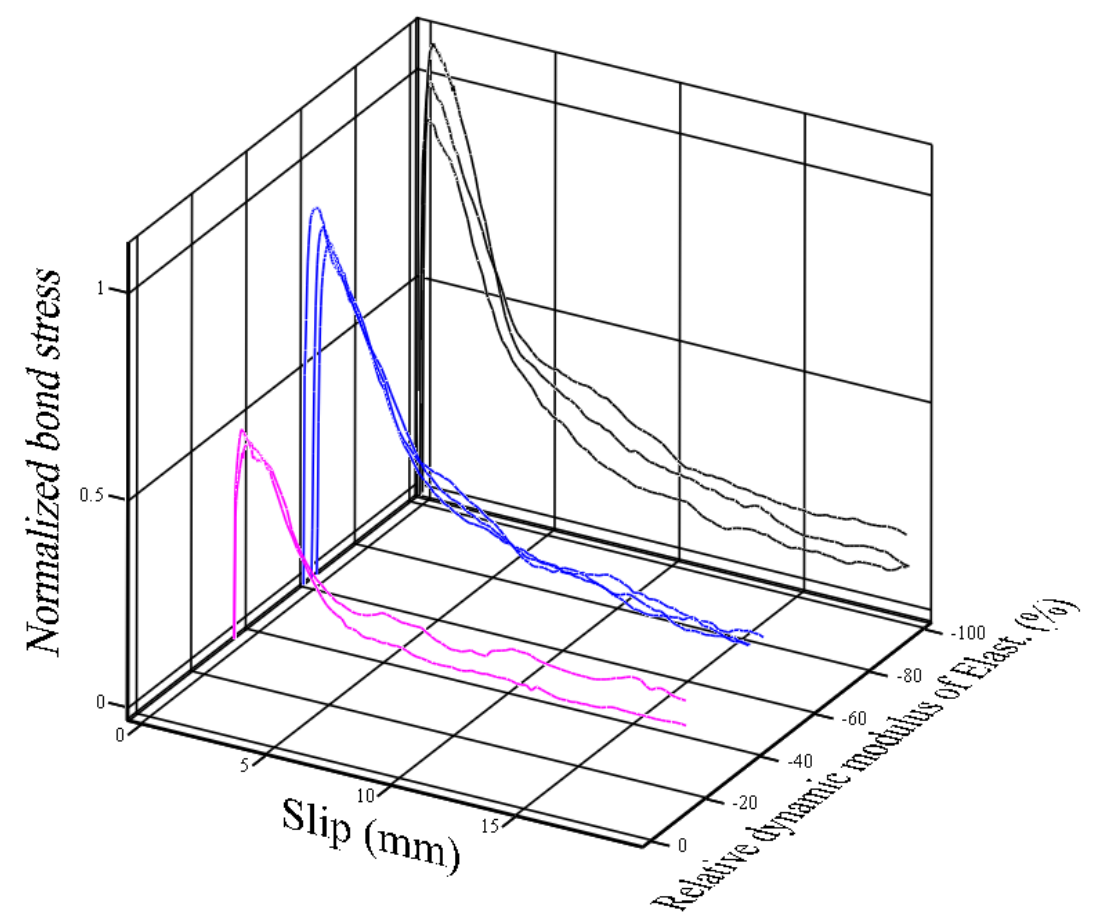

Figure 13 Bond-slip response for different levels of frost damage characterized by relative dynamic modulus of elasticity 
All tests resulted in pull-out failure at steel stresses below the yield strength, and the failure mode was characterized by shear sliding along the gross perimeter of the rebar. The average bond stress-slip response of the reference specimen, and frost damage levels I and II is shown in Figure 14 (a). It can be seen that the bond capacity is reduced by $14 \%$ and $50 \%$ for damage levels I and II, respectively. The stiffness of the ascending branch of the bond-slip response decreased with frost damage; see Figure 14 (b). Moreover, the slip at the maximum force increased with frost damage $(0.39,0.48$ and $0.60 \mathrm{~mm}$ for the reference, and damage levels I and II, respectively). The bond stress remained more or less constant over a limited range before dropping.

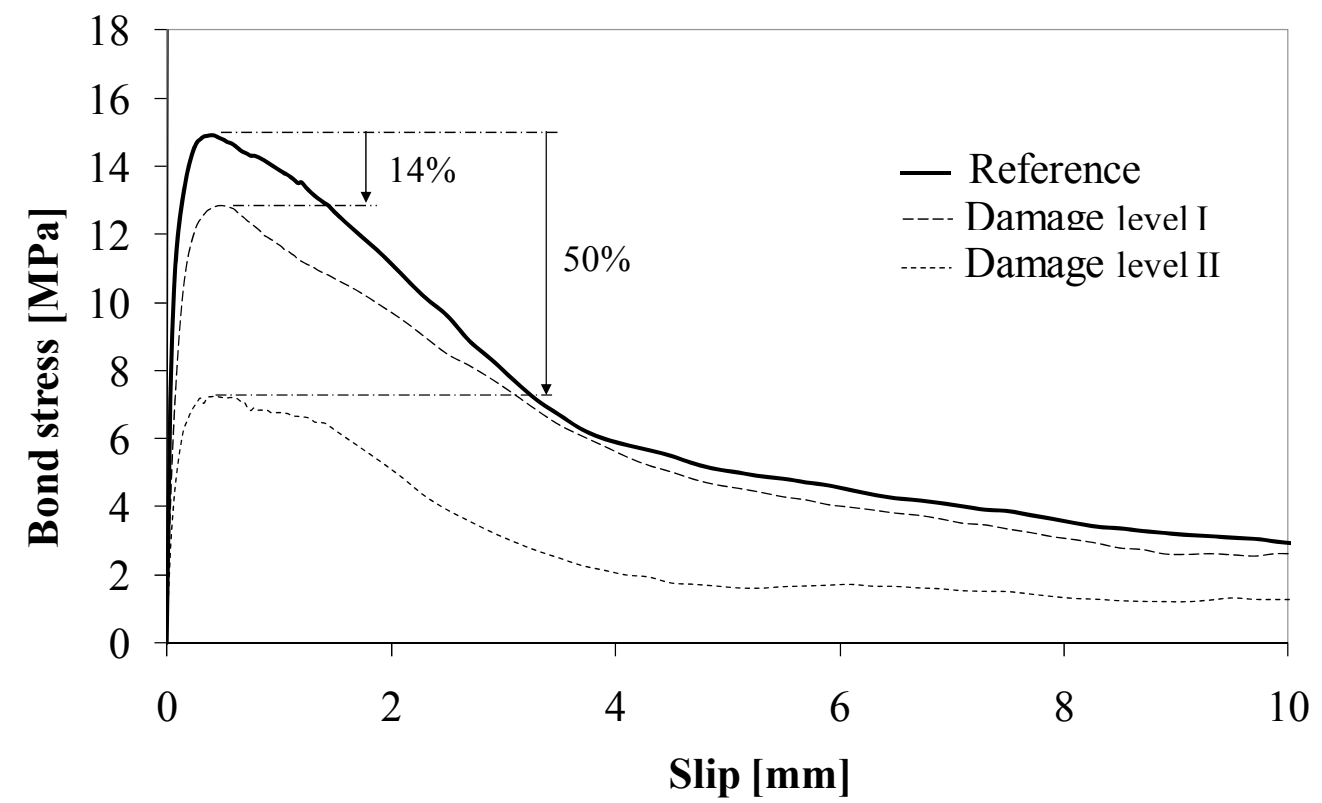

(a)

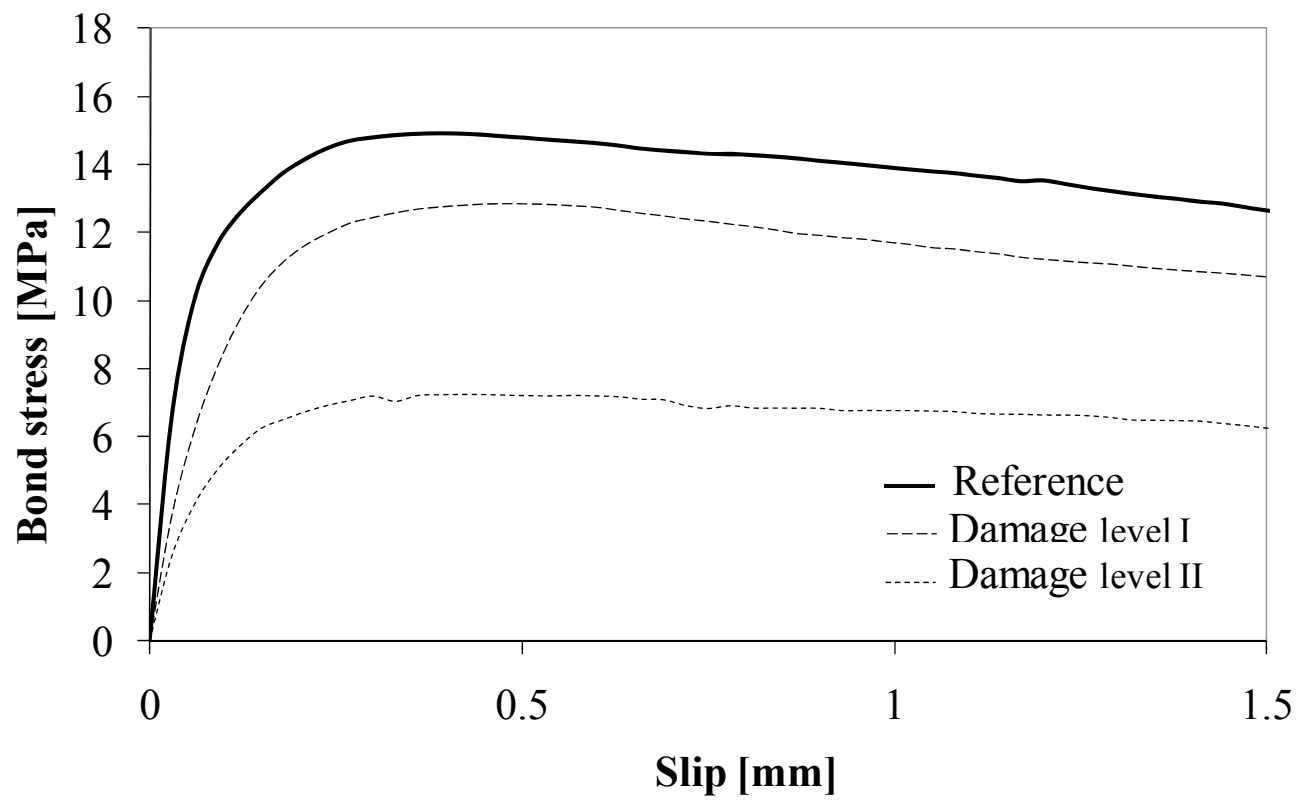

(b)

Figure 14 (a) Bond-slip response, and (b) ascending branch in bond-slip response 


\subsection{Discussion}

The first step in assessment of an existing structure subjected to freeze-thaw cycles is to quantify the frost damage. Frost damage can be quantified in terms of the number of freezethaw cycles, change in the relative dynamic modulus of elasticity or change in material properties such as compressive strength. To explain what is the most accurate and informative method of frost damage quantification, some understanding of frost damage mechanisms is required. There exist several mechanisms explaining frost phenomena in concrete, such as "Freezing of a closed container", "Hydraulic Pressure", "Microscopic ice lens growth" and "Macroscopic ice lens growth" [2]. Although none of the mechanisms were proved to explain the phenomena involved completely, each contributes to some aspect of frost damage in concrete. What is common in the mechanisms mentioned above is that, although some cycles of freezing and thawing are required before frost damage occurs in concrete, it is the degree of saturation of concrete which controls when the damage takes place and how severe it is. Hence, the damage depends on the internal structure of concrete, e.g. porosity, than on the number of freeze-thaw cycles. There are several research publications in which the frost damage has been quantified by the number of freeze-thaw cycles $[9,23,24]$. On the other hand, frost damage changes the internal structure of concrete, for example by, introducing micro and macro cracks. Any change in the internal structure of concrete affects its material properties and lengthens the travel time of an ultrasonic wave through it. For this reason, change in the material properties of concrete and change in the relative dynamic modulus of elasticity were used in this study to quantify the frost damage. Correlation between the degree of damage and the number of freeze-thaw cycles was not a central theme in the present paper, or in some other research work [7,10,25].The pull-out test results are discussed and compared with pull-out tests of frost-damage concrete found in the literature. A brief description of the experiments from the literature is given below.

Fagerlund et al. [26] have made several pull-out tests on cylinders with variations of concrete cover, embedment length, rebar type and water/cement ratio. Their test series which resulted in pull-out failure was chosen for comparison, see Table 8 . They selected degrees of frost damage produced by "evacuating" the pre-dried specimens to differing residual pressures. Then, water was introduced in the vacuum chamber and the specimens were allowed to draw in water so that different degrees of saturation were reached. The higher the vacuum pressure is, the higher the degree of saturation and the more severe the frost damage is. The specimens were exposed to seven freeze-thaw cycles, each cycle with a duration of two days, and a minimum temperature of $-18^{\circ} \mathrm{C}$. Subsequently, the damage caused by freezing was quantified by the dynamic modulus of elasticity, the cube strength and the splitting tensile strength.

Table $8 \quad$ Pull-out tests of frost-damaged concrete; here $l_{b}$ is the embedment length, $d_{s}$ is the rebar diameter and $c$ is the concrete cover.

\begin{tabular}{c|c|c|c|c|c|c|c|c|c|c}
\hline Reference & $\begin{array}{c}\text { Test } \\
\text { ID }\end{array}$ & $w / c$ & $\begin{array}{c}f_{\mathrm{cm}} \\
{[\mathrm{MPa}]}\end{array}$ & $\begin{array}{c}l_{\mathrm{b}} \\
{[\mathrm{mm}]}\end{array}$ & $\begin{array}{c}d_{\mathrm{s}} \\
{[\mathrm{mm}]}\end{array}$ & $\begin{array}{c}\text { Specimen } \\
{[\mathrm{mm}]}\end{array}$ & $\begin{array}{c}\text { Air } \\
\text { entr. }\end{array}$ & $\begin{array}{c}c \\
{[\mathrm{~mm}]}\end{array}$ & $\begin{array}{c}\text { Rebar } \\
\text { config. }\end{array}$ & $\begin{array}{c}\text { Failure } \\
\text { mode }\end{array}$ \\
\hline $\begin{array}{c}\text { Present } \\
\text { study }\end{array}$ & --- & 0.57 & 40.58 & 18 & $\begin{array}{c}\text { Ribbed } \\
\varnothing 6\end{array}$ & $\begin{array}{c}\text { Cylinder } \\
200 \times 100\end{array}$ & $0 \%$ & $\sim 47$ & Centric & Pull-out \\
\hline $\begin{array}{c}\text { Petersen } \\
\text { et al. }[10]\end{array}$ & $\mathrm{A}$ & 0.6 & 35.25 & 74 & $\begin{array}{c}\text { Ribbed } \\
\varnothing 16\end{array}$ & $\begin{array}{c}\text { Cube } \\
150\end{array}$ & $1 \%$ & $\begin{array}{c}\sim 107^{*} \\
\sim 27^{* *}\end{array}$ & Eccen. & $\begin{array}{c}\text { Close to } \\
\text { pull-out }\end{array}$ \\
\cline { 2 - 10 } & $\mathrm{B}$ & 0.7 & 29.8 & 74 & $\begin{array}{c}\text { Ribbed } \\
\varnothing 16\end{array}$ & $\begin{array}{c}\text { Cube } \\
150\end{array}$ & $1.5 \%$ & $\begin{array}{c}\sim 107^{*} \\
\sim 27^{* *}\end{array}$ & Eccen. & $\begin{array}{c}\text { Close to } \\
\text { pull-out }\end{array}$ \\
\hline \multirow{2}{*}{$\begin{array}{c}\text { Fagerlund } \\
\text { et al. }[26]\end{array}$} & $\mathrm{A}$ & 0.65 & 52.7 & 48 & $\begin{array}{c}\text { Ribbed } \\
\varnothing 12\end{array}$ & $\begin{array}{c}\text { Cylinder } \\
170 \times 187\end{array}$ & $0 \%$ & $\sim 87.5$ & Centric & Pull-out \\
\cline { 2 - 10 } & $\mathrm{B}$ & 0.65 & 45 & 72 & $\begin{array}{c}\text { Ribbed } \\
\varnothing 12\end{array}$ & $\begin{array}{c}\text { Cylinder } \\
170 \times 187\end{array}$ & $0 \%$ & $\sim 87.5$ & Centric & Pull-out \\
\hline
\end{tabular}

*Maximum concrete cover

***Minimum concrete cover 
Variation of the dynamic modulus of elasticity and bond behaviour due to frost damage has also been investigated by Petersen et al. [10], see Table 8. Cube specimens of $150 \mathrm{~mm}$ with eccentrically embedded rebar have been used for pull-out testing. The specimens were subjected to freeze-thaw cycles in accordance with the CIF test [13] until defined states of damage were reached. The state of damage has been defined by the decrease of the relative dynamic modulus of elasticity measured in the middle of the concrete cover.

Figure 15 shows the variation of bond strength normalized with respect to the mean bond strength of reference concrete versus the relative dynamic modulus of elasticity from the pullout tests. Petersen et al. [10] have proposed a linear relationship, Eq. (6), between the bond strength and the relative dynamic modulus of elasticity:

$$
\tau_{\max }=0.7 E_{\text {rel, }, y n}+17 \quad[\mathrm{MPa}]
$$

where $\tau_{\max }$ is the bond strength and $E_{\text {rel,dyn }}$ is the relative dynamic modulus of elasticity. Another relationship, Eq. (7), proposed by Fagerlund et al. [2] suggests assuming that $50 \%$ of the bond is lost due to frost effect no matter how severe the frost damage is:

$$
\tau_{\text {max,damaged }}=0.5 \tau_{\text {max }, \text { undamaged }}
$$

where $\tau_{\text {max,damaged }}$ and $\tau_{\text {max,undamaged }}$ are the bond strength of damaged and undamaged concrete, respectively. The relation given in Eq. (6) fits reasonably well with the test results of Petersen et al. [10]. From the test results plotted in Figure 15, several specimens show larger reduction of bond capacity than that proposed in Eq. (7). On the other hand, 50\% reduction of bond capacity is far within a margin of safety in several of the tests plotted in Figure 15.

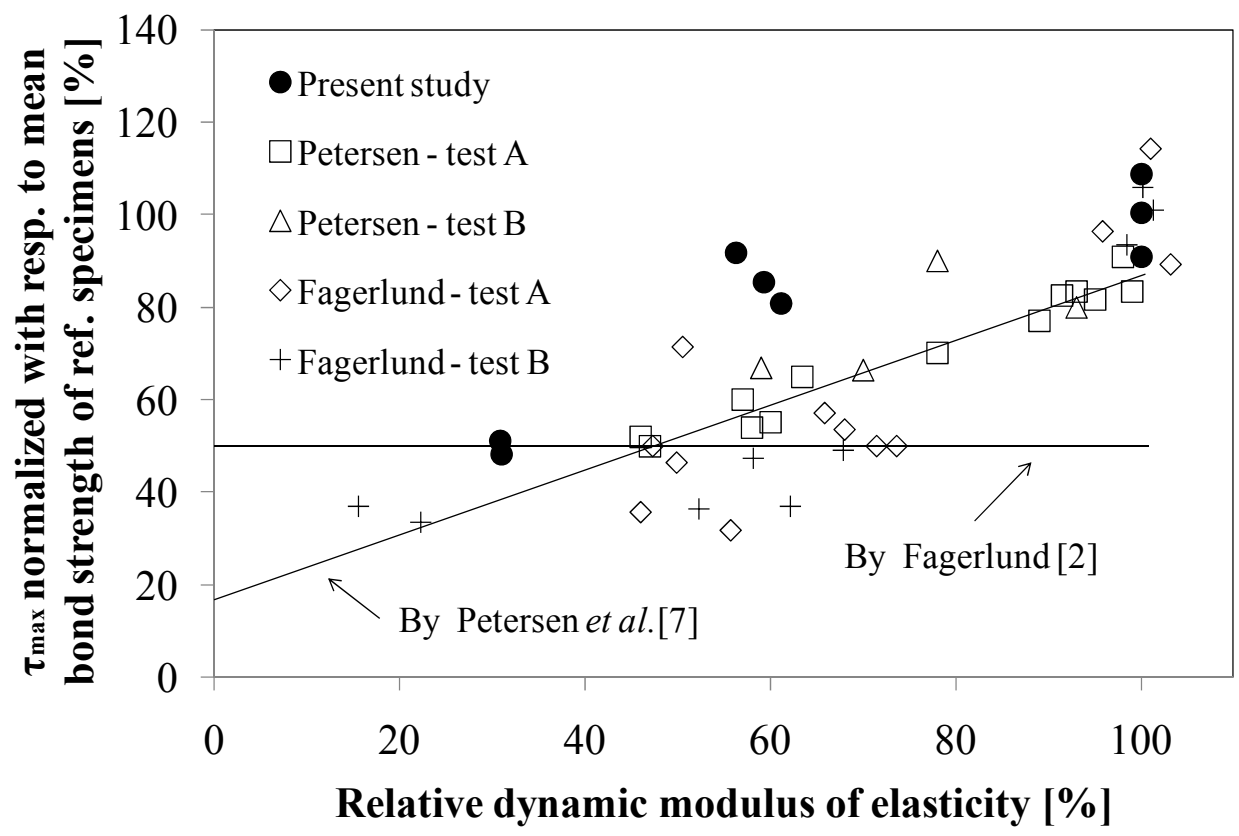

Figure 15 Bond strength versus relative dynamic modulus of elasticity.

Figure 16 shows that the slip values at the maximum bond stress generally increase with increasing damage level quantified, based on the relative dynamic modulus of elasticity. However, some reduction of the slip values at the maximum bond stress can be seen in the 
experiments of Petersen et al. [10] when there is only small amount of damage. As explained by them, the internal damage at the beginning is only taking place in the area of the concrete cover. At this level of frost-damage, the stress-strain behaviour of the concrete close to the rebar is unchanged. The curve for this specimen follows initially, before reaching the maximum bond stress, the curve for the undamaged specimen. For this specimen, however, the maximum bond stress is lower because of the internal damage in the concrete cover. Therefore, the specimens with such a low level of damage show a decrease of the slip at the maximum bond stress.

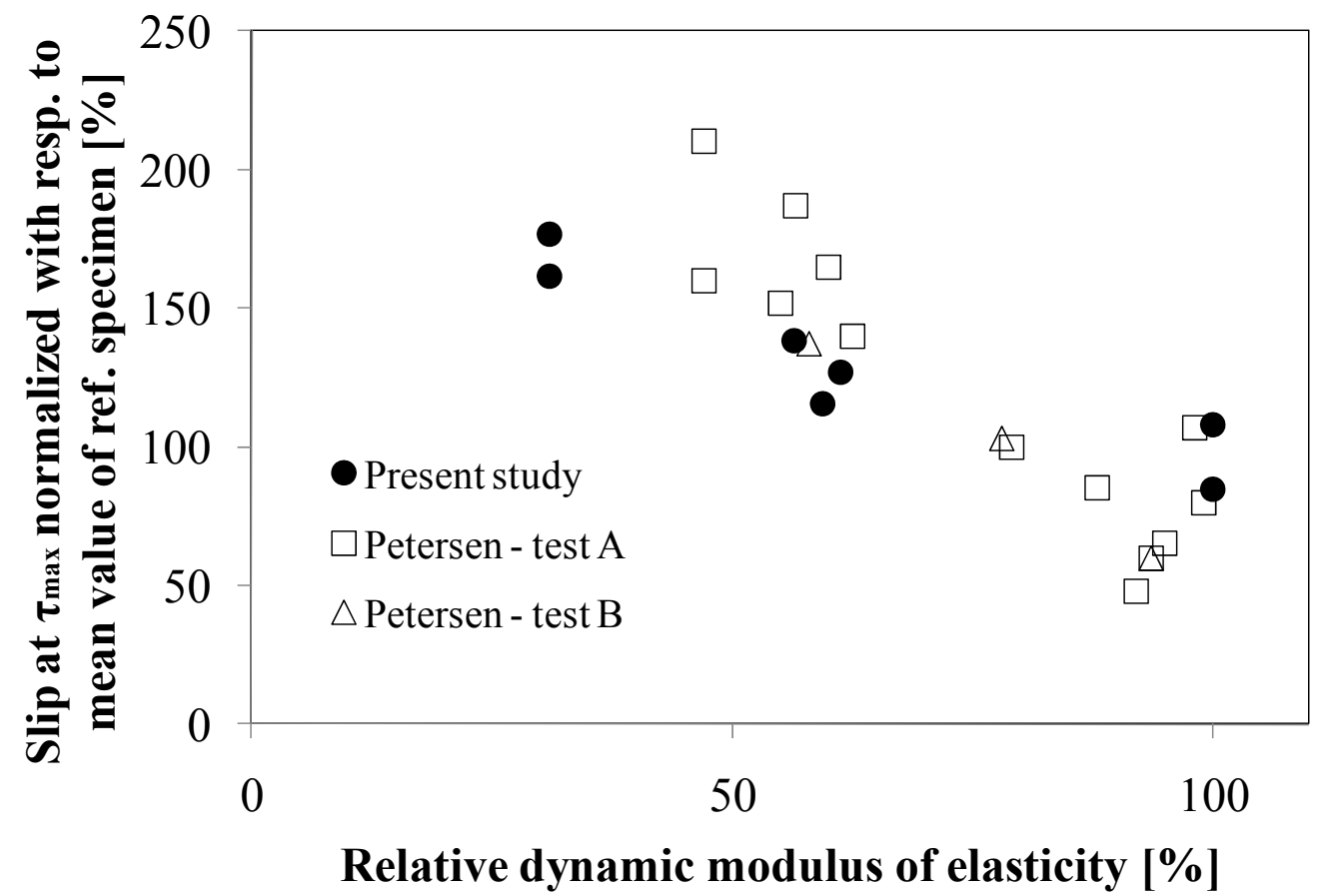

Figure 16 Slip at maximum bond versus relative dynamic modulus of elasticity.

\section{CONCLUSIONS}

In an experimental study, the effect of frost damage on the material and bond properties of concrete was investigated. The level of frost damage was quantified using ultrasonic measurements together with the compressive strength of concrete. Compression tests and elastic modulus tests were conducted to study the concrete behaviour in compression, and the tensile behaviour of frost-damage concrete was investigated by splitting tensile tests and wedge splitting tests. Inverse analysis of wedge splitting test results led to estimations of the $\sigma-w$ relation for both reference and frost-damaged concrete. Finally, pull-out tests were performed to evaluate the effect of frost damage on the bond between the reinforcement and the concrete.

The test results showed significant change in the material and bond properties of frostdamaged concrete when compared with reference concrete. The first level of damage, defined as $25 \%$ reduction in compressive strength of concrete, corresponded to $29 \%, 43 \%$ and $14 \%$ reductions in tensile strength, elastic modulus and bond strength. For the second level of damage, defined as $50 \%$ reduction in the compressive strength of concrete, these properties were decreased by $63 \%, 84 \%$ and $50 \%$. The shape of the compressive stress-strain curve of frost-damaged concrete differed significantly from that of undamaged concrete. From wedge 
splitting test results, an increase in the fracture energy due to frost damage was observed, which can be explained by the introduction of several cracks as an effect of the frost damage prior to mechanical testing. Thus, greater energy was dissipated, by opening several dominant cracks, to fully fracture the specimen. The tensile stress-crack opening relation, $\sigma-\omega$, estimated from experiments shows a very large ultimate crack opening which could not be predicted by the Hordijk et al. model. The pull-out test results showed a significant change in the bond properties of frost-damage concrete compared to reference concrete, i.e. the slip at the maximum bond stress increased with frost damage.

\section{REFERENCES}

[1] K. Zandi Hanjari, Load-Carrying Capacity of Damaged Concrete Structures, Licentiate thesis, Civil and Environmental Engineering, Chalmers University of Technology, Gothenburg, Sweden, 2008.

[2] G. Fagerlund, G. Somerville, J. Jeppson, Manual for Assessing Concrete Structures Affected by Frost, Division of Building Materials, Lund Institute of Technology, Lund, Sweden, 2001.

[3] J. J. Valenza, G. W. Scherer, Mechanism for salt scaling, J Am Ceram Soc 89 (4) (2006) 1161-1179.

[4] T. C. Powers, A working hypothesis for further studies of frost resistance of concrete, Journal of American Concrete Institute 16 (4) (1945) 245-271.

[5] J. J. Beaudoin, C. Macinnis, The mechanism of frost damage in hardened cement paste, Cem Concr Res 4 (2) (1974) 139-147.

[6] P. Utgenannt, The Influence of Ageing on the Salt-frost Resistance of Concrete, Doctoral thesis, Division of Building Materials, Lund Institute of Technology, Lund, Sweden, 2004.

[7] M. Hasan, H. Okuyama, Y. Sato, T. Ueda, Stress-strain model of concrete damaged by freezing and thawing cycles, Journal of Advanced Concrete Technology 2 (1) (2004) 89-99.

[8] M. Hasan, T. Ueda, Y. Sato, Stress-Strain relationship of frost-damaged concrete subjected to fatigue loading, J Mater Civ Eng 20 (1) (2008) 37-45.

[9] T. S. Shih, G. C. Lee, K. C. Chang, Effect of freezing cycles on bond strength of concrete, J Struct Eng-ASCE 114 (3) (1988) 717-726.

[10] L. Petersen, L. Lohaus, M. A. Polak, Influence of freezing-and-thawing damage on behavior of reinforced concrete elements, ACI Mater J 104 (4) (2007) 369-378.

[11] K. Zandi Hanjari, Material and Bond Properties of Frost-Damaged Concrete, Report 2008:10, Civil and Environmental Engineering, Chalmers University of Technology, Gothenburg, Sweden, 2008.

[12] L. Tang, P. E. Petersson, Slab test: Freeze/thaw resistance of concrete - Internal deterioration, Mater Struct 37 (274) (2004) 754-759.

[13] M. J. Setzer, P. Heine, S. Kasparek, S. Palecki, R. Auberg, V. Feldrappe, E. Siebel, Test methods of frost resistance of concrete: CIF-Test: Capillary suction, internal damage and freeze thaw test - Reference method and alternative methods A and B, Mater Struct 37 (274) (2004) 743-753.

[14] M. J. Setzer, D. J. Janssen, R. Auberg, D. H. Bager, G. Gudmundsson, S. Jacobsen, T. Miura, H. Mihashi, V. Penttala, P.-E. Petersson, E. M. Schulson, J. Stark, L. Tang, P. Ursella, RILEM TC 176-IDC: Internal damage of concrete due to frost action: Final Report, Mater Struct 37 (274) (2004) 740-742. 
[15] H. S. Shang, Y. P. Song, Experimental study of strength and deformation of plain concrete under biaxial compression after freezing and thawing cycles, Cem Concr Res 36 (10) (2006) 1857-1864.

[16] M. Hassanzadeh, G. Fagerlund, Residual strength of the frost-damaged reinforced concrete beams, III European Conference on Computational Mechanics Solids, Structures and Coupled Problems in Engineering, Lisbon, Portugal, 5-8 June, 2006.

[17] T. Ueda, M. Hasan, K. Nagai, Y. Sato, L. Wang, Mesoscale simulation of influence of frost damage on mechanical properties of concrete, J. Mater. Civ. Eng. 21 (6) (2009) 244-252.

[18] G. Fagerlund, A Service Life Model for Internal Frost Damage in Concrete, Division of Building Materials, Lund Institute of Technology, Lund, Sweden, 2004.

[19] J. L. A. de Oliveira e Sousa, R. Gettu, Determining the tensile stress-crack opening curve of concrete by inverse analysis, J Eng Mech-ASCE 132 (2) (2006) 141-148.

[20] I. Löfgren, Fiber-reinforced Concrete for Industrial Construction - A Fracture Mechanics Approach to Material Testing and Structural Analysis, Doctoral thesis, Structural Engineering and Mechanics, Chalmers University of Technology, Gothenburg, Sweden, 2005.

[21] L. Østergaard, Early-age Fracture Mechanics and Cracking of Concrete - Experiments and Modelling, Doctoral thesis, Department of Civil Engineering, Technical University of Denmark, Copenhagen, 2003.

[22] H. A. W. Cornelissen, D. A. Hordijk, H. W. Reinhardt, Experimental determination of crack softening characteristics of normalweight and lightweight concrete, Heron 31 (2) (1986) 45-56.

[23] J.-X. Gong, S.-Q. He, Y.-X. Guo, Influence of freezing and thawing cycles on bond characteristics of steel bar and concrete in salt environment, Journal of Dalian University of Technology 45 (3) (2005) 405-409.

[24] X. Ji, Y. Song, Y. Liu, Effect of freeze-thaw cycles on bond strength between steel bars and concrete, J Wuhan Univ Technol-Mat Sci Edit 23 (4) (2008) 584-588.

[25] W. Sun, Y. M. Zhang, H. D. Yan, R. Mu, Damage and damage resistance of high strength concrete under the action of load and freeze-thaw cycles, Cem Concr Res 29 (9) (1999) 1519-1523.

[26] G. Fagerlund, M. Janz, B. Johannesson, Effect of Frost Damage on the Bond between Reinforcement and Concrete, Report, Division of Building Materials, Lund Institute of Technology, Lund, Sweden, 1994. 